\title{
المعايير العامة لتسعير المنتجات في السوق الإسلامية
}

\author{
نعيم حنك \\ الجامعة الإسلامية العالمية- كلية معارف الوحي- قسم الفقه وأصوله- ماليزيا \\ naim.hank@gmail.com
}

تتناول هذه الدراسة بالبحث والتحليل عملية التسعير في الشريعة الإسلامية. مع الإشارة إلى آليات التسعير في التمويل

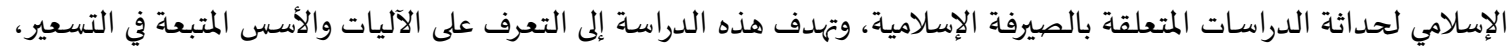

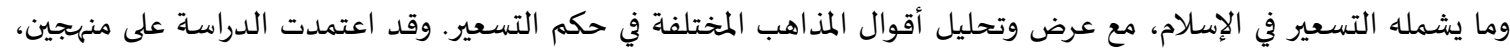

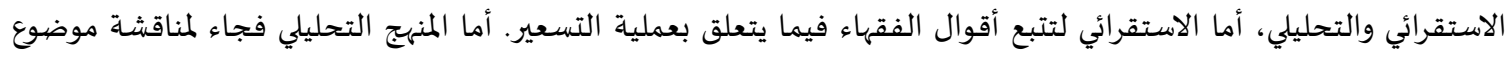

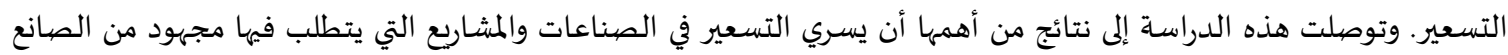

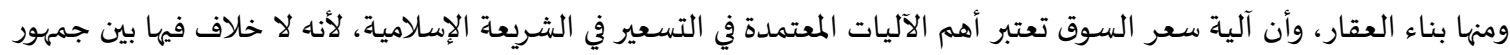

\section{@) (1)}

الكلمات المفتاحية: التسعير ، آليات التسعير ، معايير التسعير ، حكم التسعير.

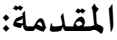

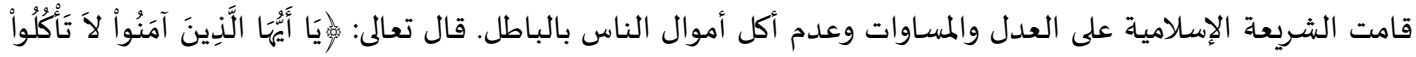

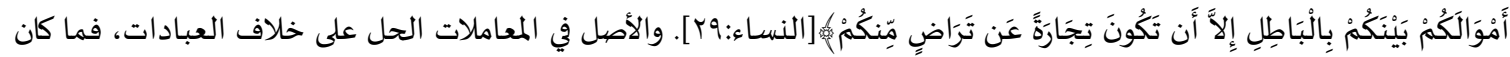

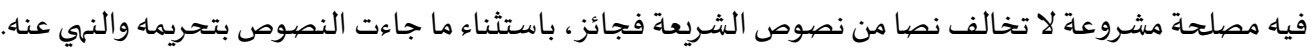

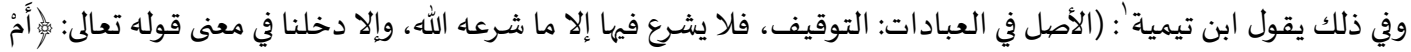

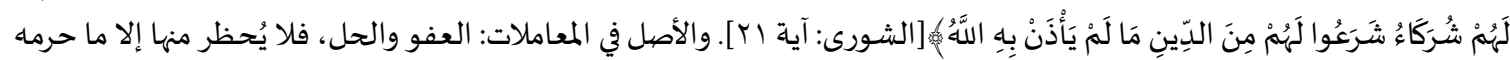

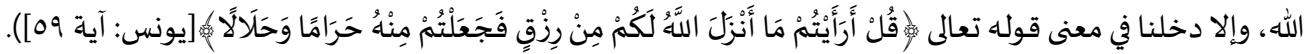

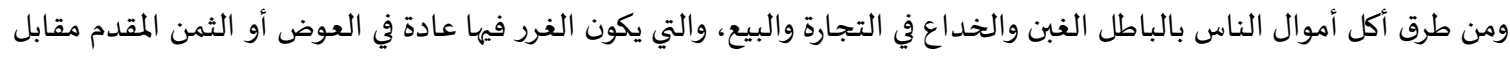

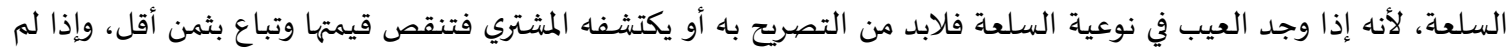

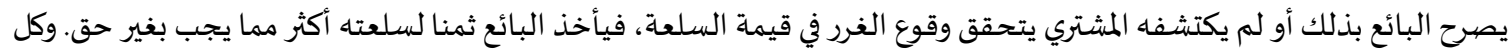

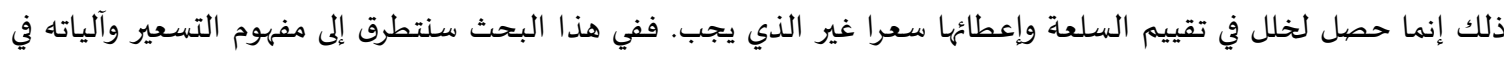
الشريعة الإسلامية مع ذكر مذاهب الفقهاء في ذلك.

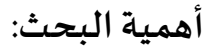

تبرز أهمية هذا البحث في أنه تطرق إلى أهم الآليات التي تتم بها عملية التسعير في الشريعة الإسلامية، مع إبراز أقوال الفقهاء وآرائهم في حكم التسعير وأثر اختلافهم على تلك الآليات.

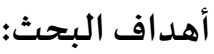

يأمل الباحث من خلال هذه الدراسة تحقيق الأهداف التالية:

بيان الآليات العامة للتسعير في الشريعة الإسلامية لهدالية

'ابن تيمية، تقي الدين أبو العباس أحمد بن عبد الحليم، الفتاوى الكبرى، تحقيق: محمد عبدالقادر عطا ومصطفى عبدالقادر عطا (بيروت: دار الكتب 


$$
\text { إبراز الحكم الشرعي للآليات المعتمدة في التسعير. }
$$

توضيح أثر اختلاف المذاهب الفقهية في حكم التسعير على آليات التسعير في السوق الإسلامية.

منهر البتحث:

يعتمد الباحث في هذه الدراسـة على منهجين رئيسيين، وهما:

المنهج الاستقرائي: لتتبع الطرق والآليات المعتبرة في عملية التسعير في الشريعة الإسلامية، واستقراء أقوال الفقهاء ومذاهبهم

• المنهج التحليلي: لتحليل المادة العلمية المجمّعة بالاستقراء، ومناقشتها للتوصل إلى النتيجة المرجوة من البحث، وأيضيا نعتمد على المنهج التحليلي من أجل دراسة أسباب اختلاف العلماء في جواز بعض آليات التسعير وعرض الآراء وبيان الراجح منها من المرجوح.

الدراسـات السـابقة: وتعددت الدراسـات في مجال التسعير قديما وحديث، ولعلنا نعتمد بعض الدراسات الحديثة خاصية منها في جانب المالية الإسلامياة، لحداثة تجربة المالية الإسالامية، وبالتالي تكون الآليات المستخرجة منها تناسب السوق الحديثة، ومن هذه الدراسات:

• الرؤى الإسلامية للسلع والخدمات ؛ لصاحبـ محمد بن أحمد بن صالح، تناول فيه الكاتب التسعير ومختلف أحكامه في الشريعة الإسلامية في ستة فصيول. فتطرق إلى مفهوم القيمة في مختلف النظريات الاقتصادية، وكذا مفهوم التسعير وحكماه في الشريعة الإسلامية وتسعير أجور الأشخاص كمثال عن تسعير الخدمات، ولعل أهم ما نضيفـه على هذا البحث هو إبراز الآلية التي من خلالها يتم تسعير المنتجات المالية الإسلامياة. محاسبة المصيارف الإسلامية : لصياحبـه حسين محمد سمحان والدكتور موسى عمر مبارك، حيث تطرق إلى مختلف العمليات التي تقوم هها البنوك الإسالامية والإجراء ات المحاسبية في هذه المعاملات، فبدأ بمحاسبة عمليات الودائع المصرفية الإسلامية ثم عمليات المرابحة والمرابحة المركبة ثم عمليات البيع الآجل ثم عمليات المضاربة ثم المشاركة المتناقصية (المنتهية بالتمليك) ثم عمليات السَّلَم ثم عمليات الاستصناع ثم عمليات التأجير ثم عمليات محاسبة الاستثمارات في الأسهم والصكوك والعقارات وفي الأخير العمليات المصرفية الخارجية في المصارف الإسلامية، ليختم مباحث الكتاب بمبحث الحسابات الختامية في المصارف الإسلامية تناول فيها الكاتب الأساليب العملية التي تتبعها المصارف الإسلامية في العمل بأموال المضياربة وأسس توزع الأرباح في المصارف الإسلامية. أكثر ما يهمنا تناول الكاتب للمحاسبة الإسلامية في عمليات المشاركة المتناقصة وأنواع المشاركات في المصارف الإسلامية وكذلك الطرق التي تعتمدها البنوك الإسلامية في القيام بالعمليات المحاسبية والتسعير. • ومن الأوراق البحثية باللغة الإنجليزية التي تناولت جانب التسعير في باب التمويل الإسلامي ورقة بعنوان:

Home Financing Pricing Issues in the Bay' Bithaman Ajil (BBA) and Musharakah Mutanaqisah (MMP) ${ }^{4}$.

(قضايا التسعير في التمويل العقاري في البيع بالثمن الآجل والمشاركة المتناقصة)، والورقة العلمية للباحثين شاهيداواتي شاهوان، ومصطفى عمر محمد، وزهر الدين عبد الرحمن، حيث تناولت الورقة تحليل قضيية التسعير في منتجات التمويل العقاري في ماليزيا، وخصت بالدراسة المشاركة المتناقصة والبيع بثمن آجل.

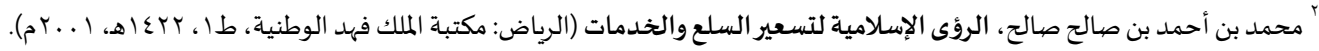

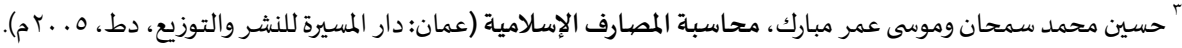

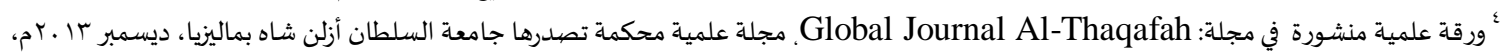
تحت رقم: (VOL 3 ISSUE 2 | 23 ISSN : 2232-0474 | E-ISSN : 2232-0482). 


\section{مصطلحات البحث:}

مفهوم التسعير:

لغة: التسعير في اللغة: تقدير السعرٌ، يقال سعرت الشيء تسعيرا: أي جعلت له سعرا معلوما ينتهي إليه. وسعروا تسعيرا أي: اتفقوا

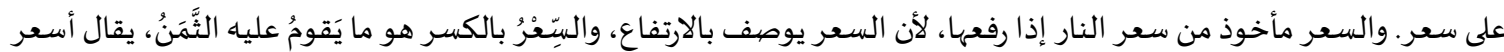

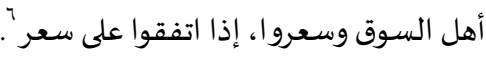

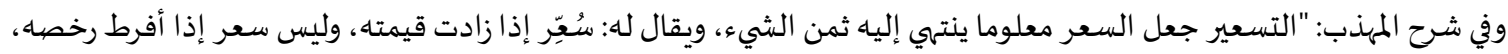

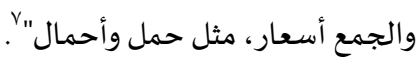

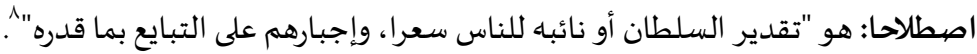

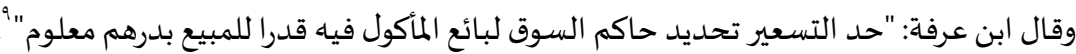

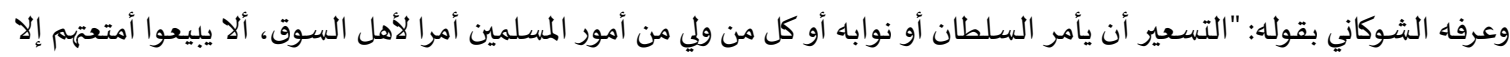

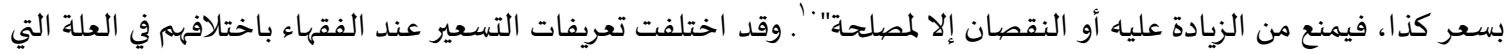

يسعر من أجلها.

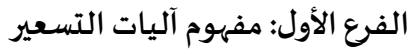

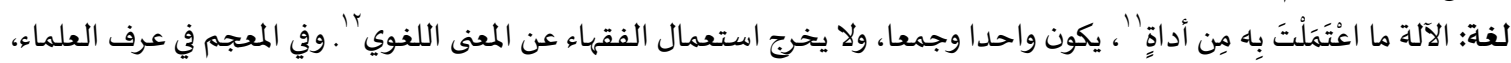

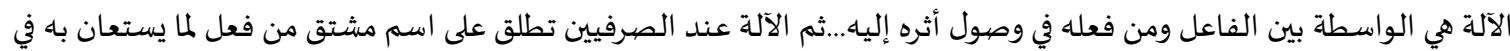

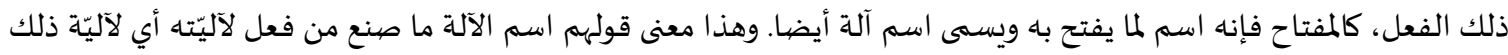

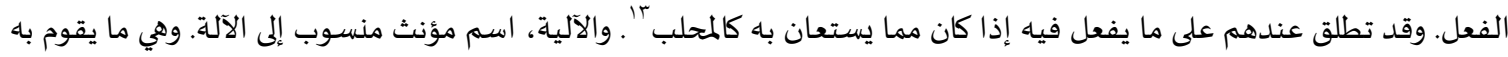
الفاعل لتحقيق المقصد باعتماده على ما عنده من وسائل وشروط تحقق ذلك المقصد وتلبي حاجتاه.

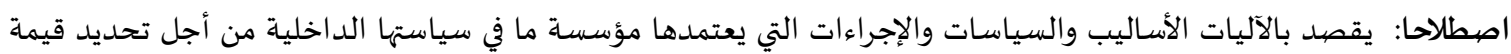

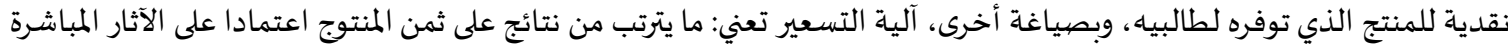

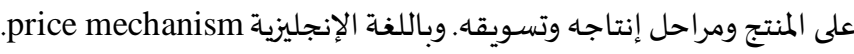
ففي أي مشروع تجاري أو استثماري مثلا، ومن أجل تحقيق أهداف المشروع، أو ضماندان تحقيق ربح العملية الاستثمارية، لابد لصاحب الصاحب

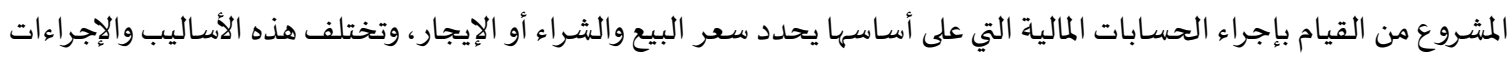

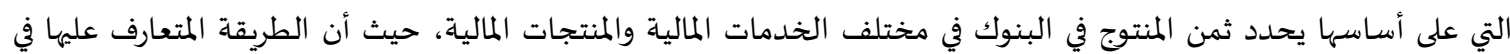
التسعير عند المؤسسات الإنتاجية هي الطريقة التقليدية، وهي حساب تكلفة المواد الأولية التي تدخل في صناعة المنتج، يضاف إلهيها

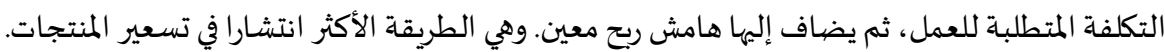

المبحث الأول: ماهية التسعير في الشريعة الإسلامية.

المطلب الأول: تعريف التسعير

تعريف الهوتي: "هو أن يسعر الإمام أو نائبه على الناس سعرا ويجبرهم على التبايع به" "ألى

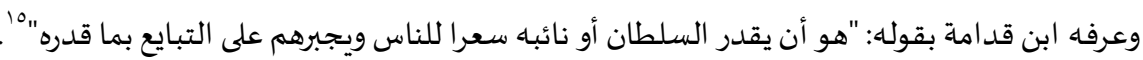

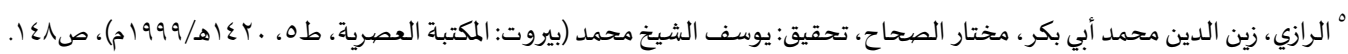

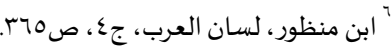

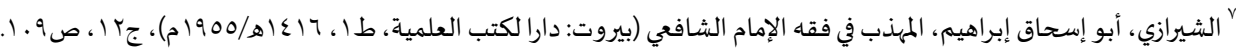

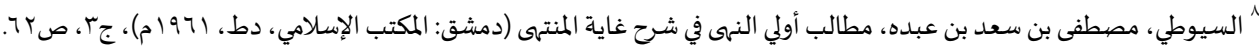

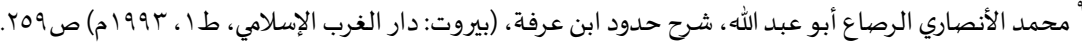

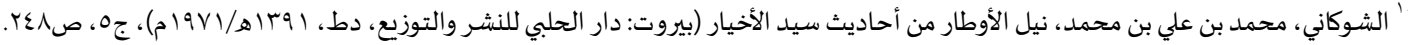

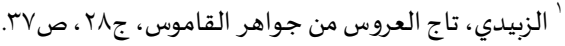

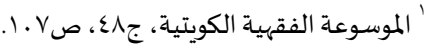

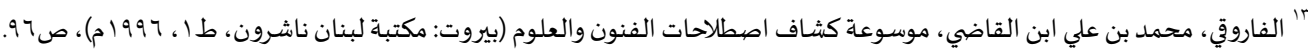

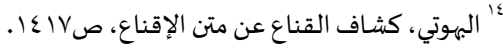




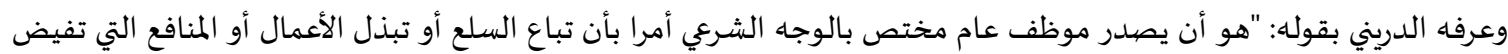

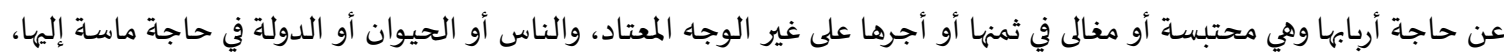

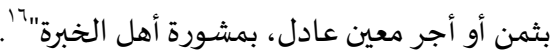

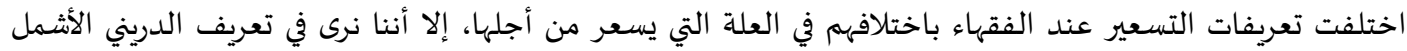

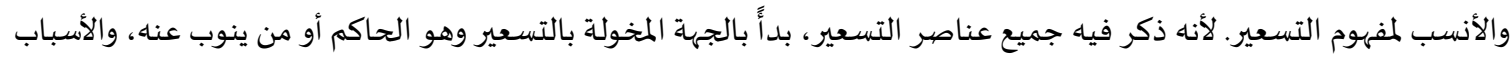

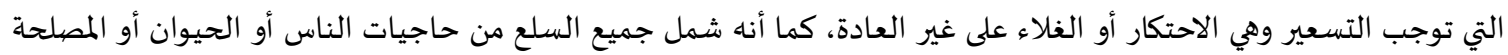

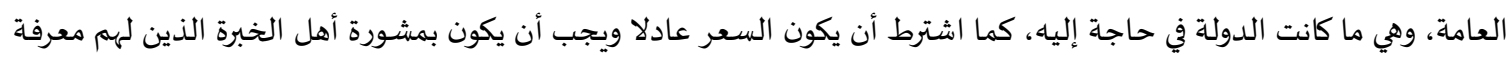
بالسوق وأحواله.

المناسبة بين التعريف اللغوي والاصطلاحي من خلال هذه التعاريف، نلاحظ المناسبة واضحة بين التعاريف اللغوية والاصطلاحية، حيث أن التسعير لا يكون إلا إذا غلا

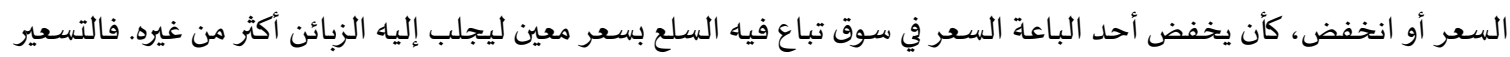

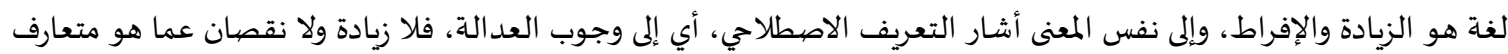

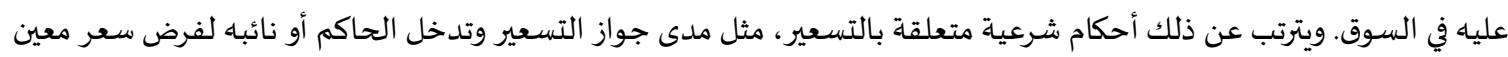
على أهل السوق، نتطرق إلهها في مباحث آتية.

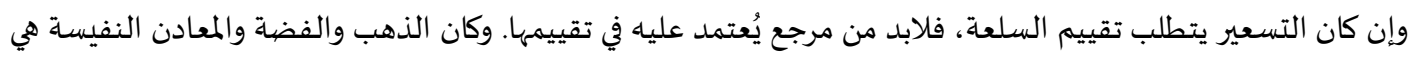

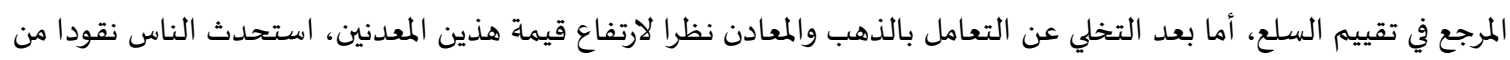

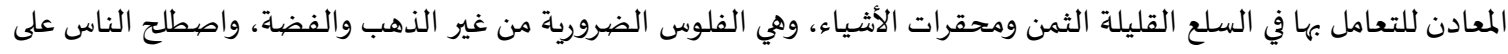

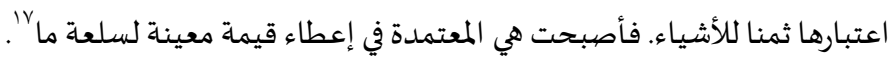
الفرق بين السعروالقيمة والثمن. والسعر هو المقدار المالي للأشياء التي تحدد في السوق، سواء زالئ المعاد على القيمة أم كان مساويا لها أم نقص. أما الثمن فهو العوض المقابل

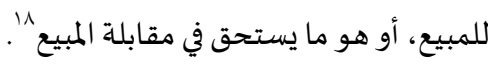

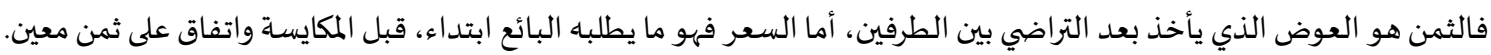

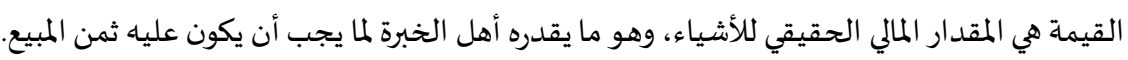

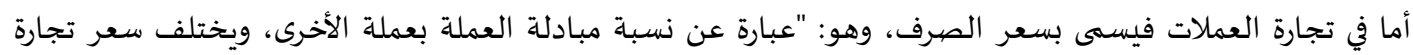

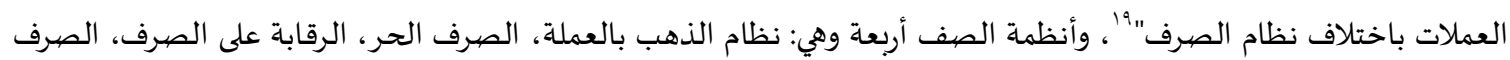

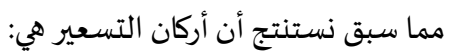

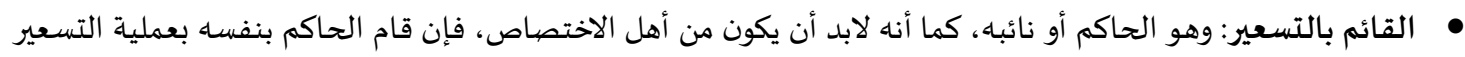

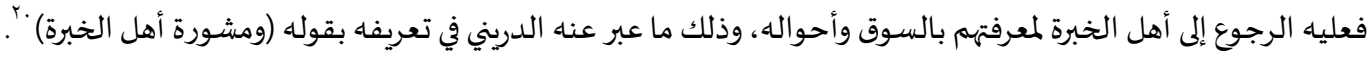

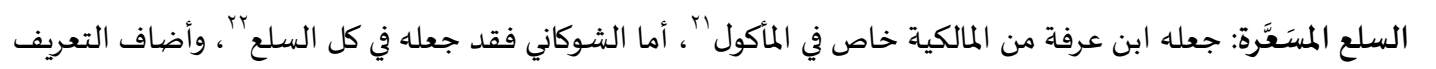

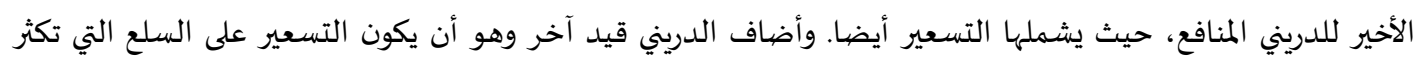
الحاجة إليها، فيغالي الباعة في أثمانها.

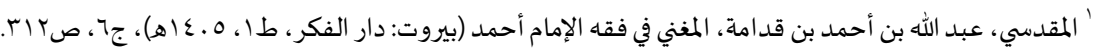

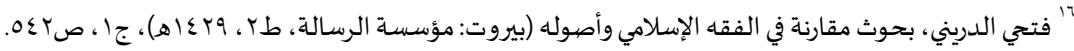

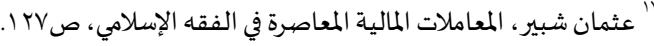

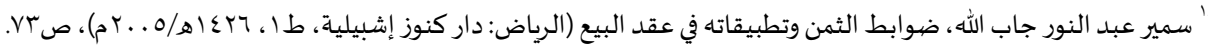

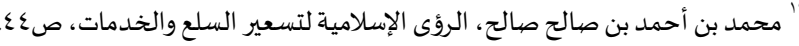

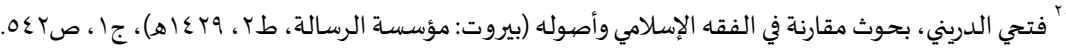

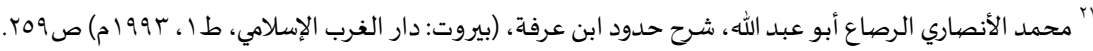

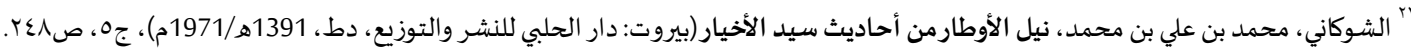




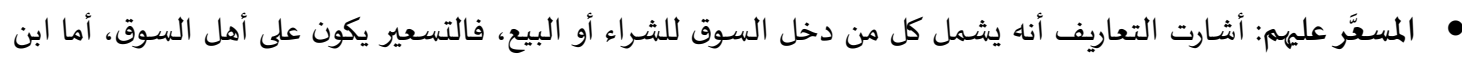

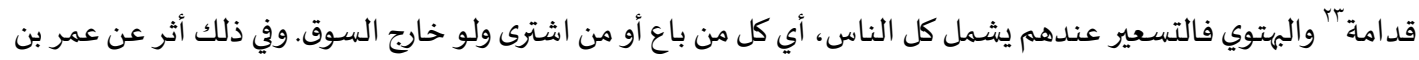

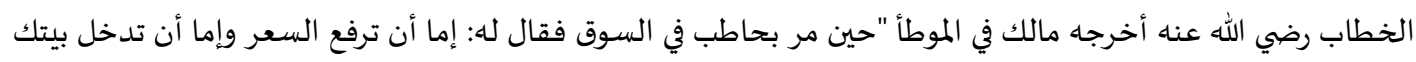

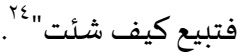

• السعر: هو المقدار المالي الذي يعطى للسلعة ويحدد لها من غير ظلم أو تعد، فيُّتقيد باه ولا يخالف.

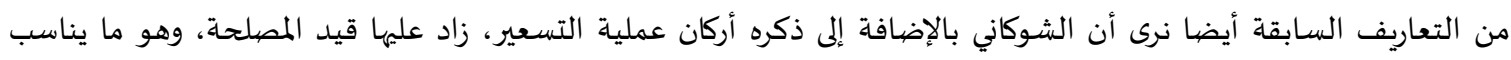
الاختلاف الفقي في جواز التسعير من عدمها.

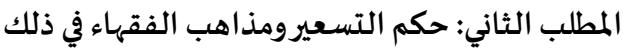

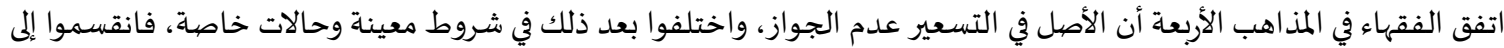

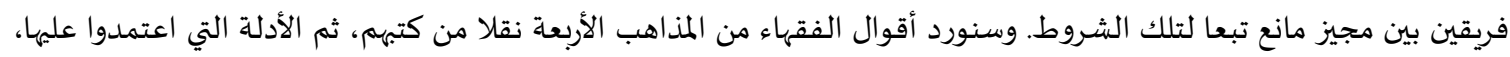

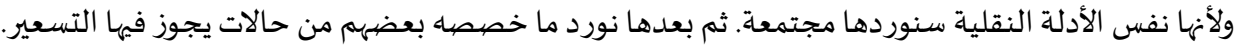

$$
\text { أولا: حكم التسعيرفي المذاهب الفقهية الادية }
$$

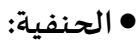

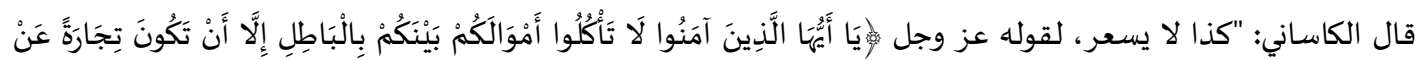

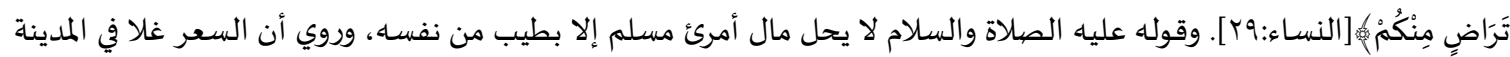

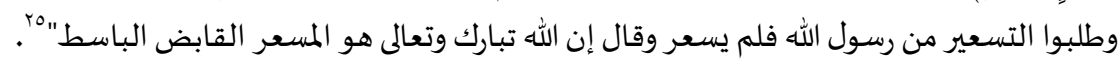

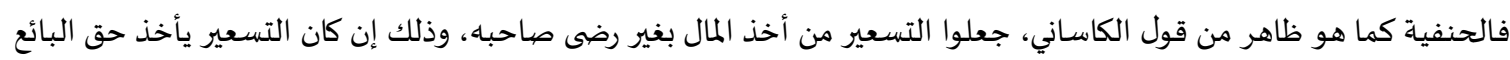

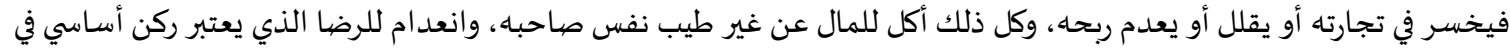

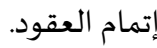

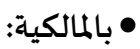

قال ابن عبد البر: "ولا يكره على أحد ماله، ولا يكره على بيع سلعته ممن لا يريد، ولا بما لا يريد، إلا أن يتبين في ذلك ضرر ألكار

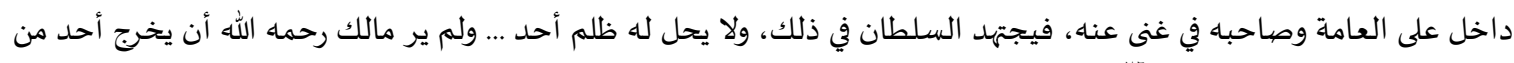

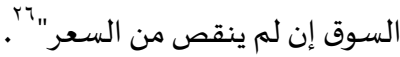

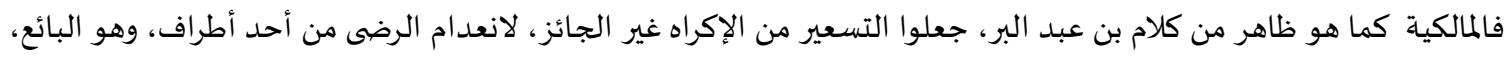

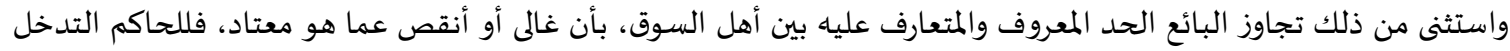

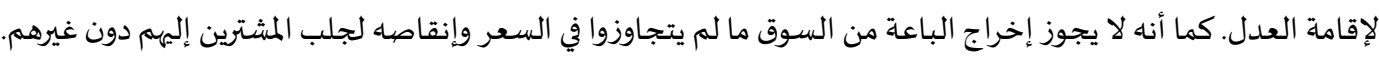

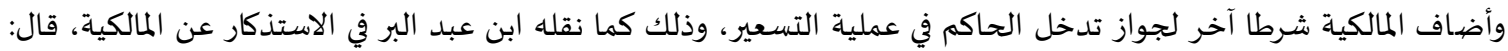

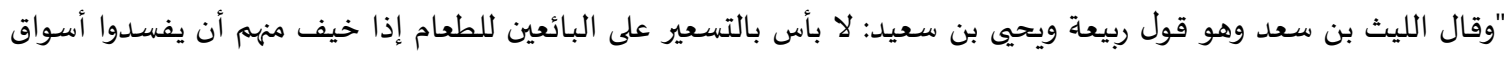

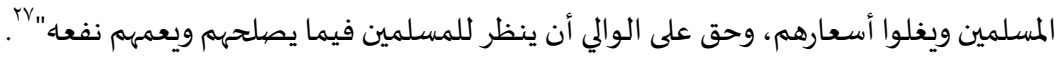

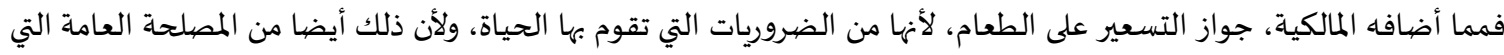

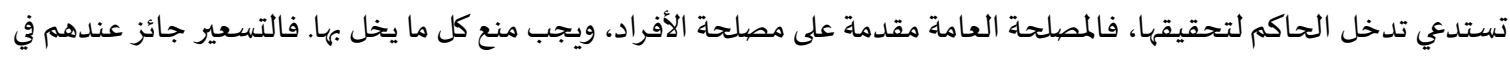

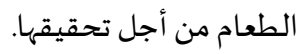

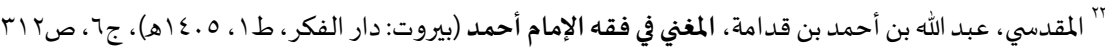

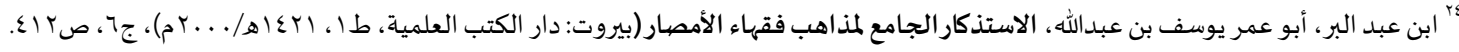

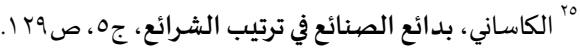

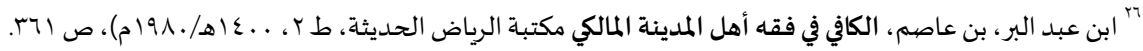

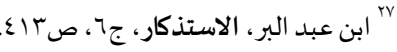




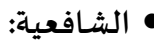

قال الشيرازي: "ولا يحل للسلطان التسعير، لما روى أنس رضي الله عنه: غلا السعر على عهد رسول الله صلى الله عليه وسلم

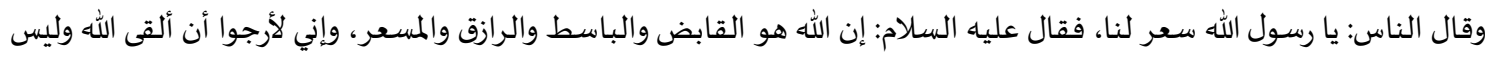

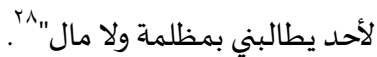

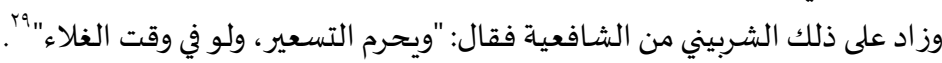

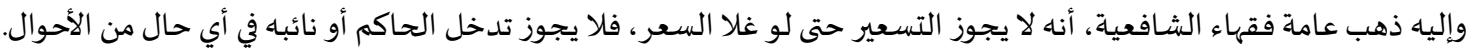

•

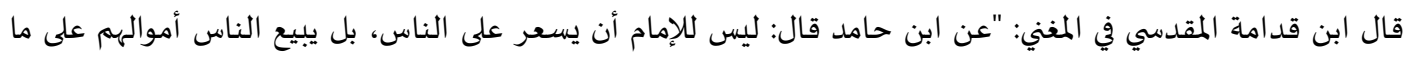

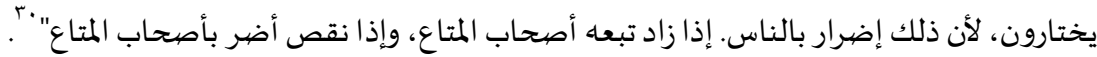

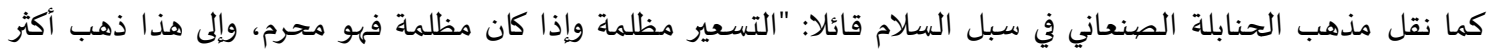

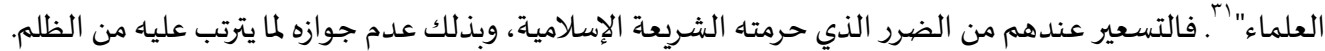

ثانيا: علاقة أوضاع السوق بالتسعير العندير

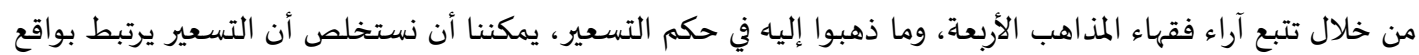

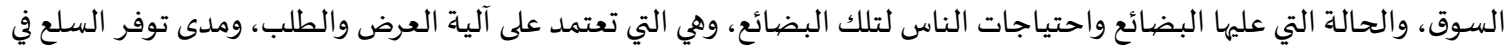
السوق لتلبية حاجيات الناس. وهذه الأحوال على قسمين: في الحالة المعتادة للسوق.

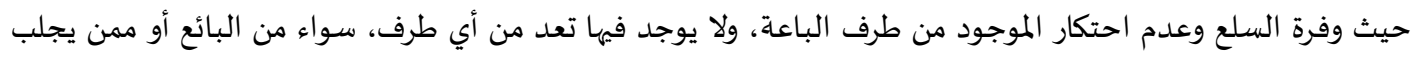

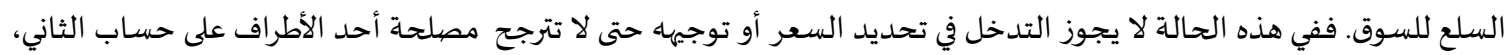

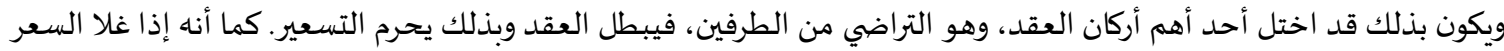

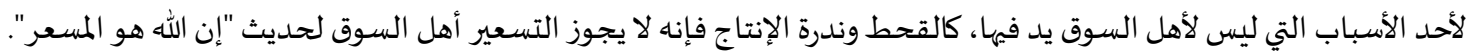
في حالة الضرورة والحاجة.

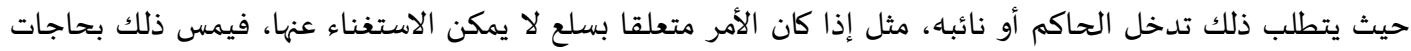

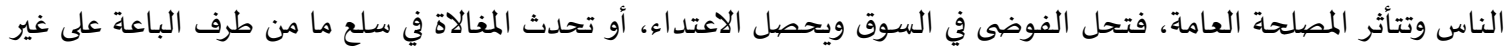
الثمن المتعارف عليه عادة. هنا يتطلب تدخل الحاكم أو نائبه، وذلك لإجبار أهل السوق على التعامل بسعر المثل. فيحصل التساتل التسعير

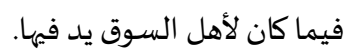

المطلب الثالث: الأدلة الواردة في حكم التسعير استدل الفقهاء من المذاهب الأربعة على ما ذهبوا إليه من أقوال سابقة بأدلة من القرآن الكريم والسنة النبوية، نوردها فيما يلي مع ذكر وجاه الدلالة منها. أولا: من القرآن الكريم

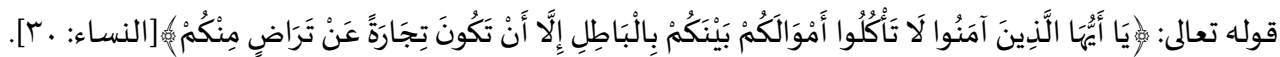

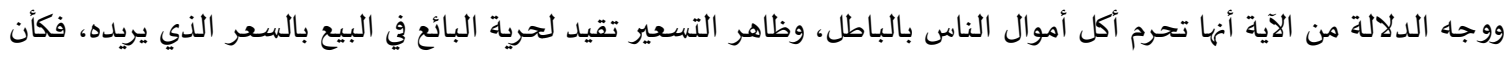

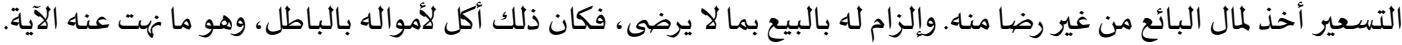

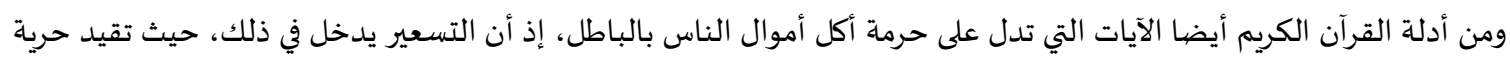
البائع أو المشتري في التصرف في ماله، وذلك من الاعتداء والظلم.

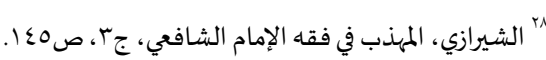

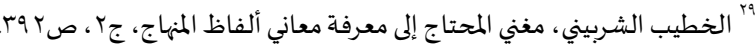

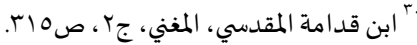

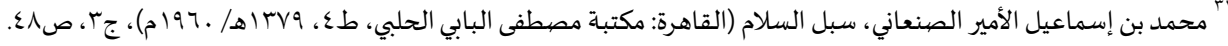


ثانيا: من السنة النبوية الشريفة

ونذكر منها أشهر حديثين يستدل بهما الفقهاء على عدم جواز التسعير، وهما حديث أنس وأبي هريرة رضي الله عنهما، وهما

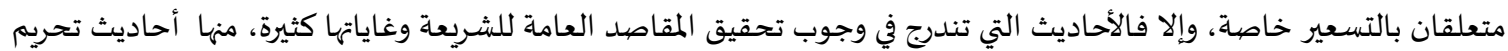

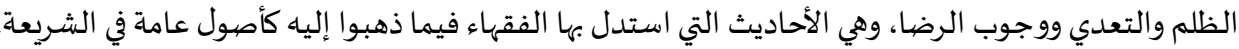

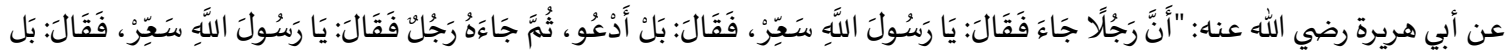

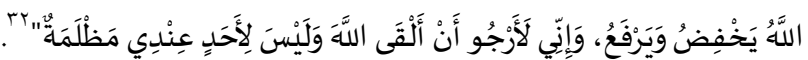

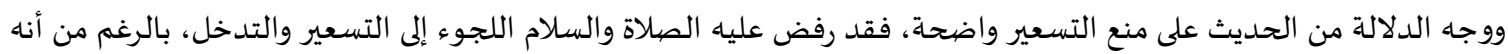

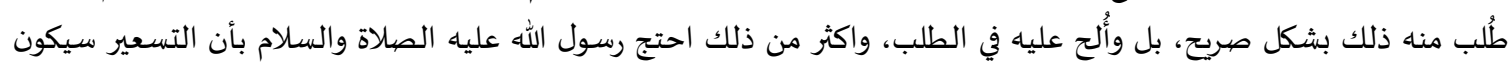
مظلمة.

قال الشوكاني في شرحه للحديث: "وقد استدل بالحديث وما ورد في معناه على تحريم التسعير وأنه مظلمة. ووجهاه أن الناس

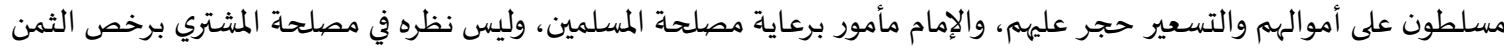

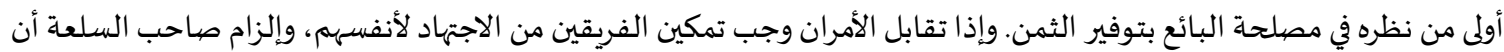

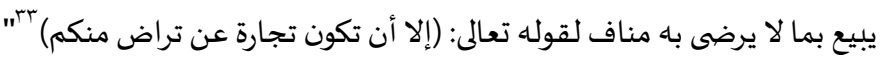

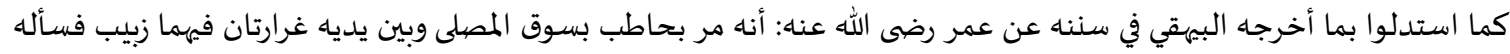

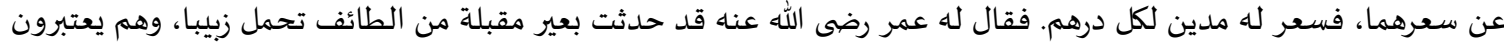

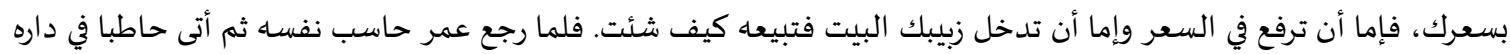

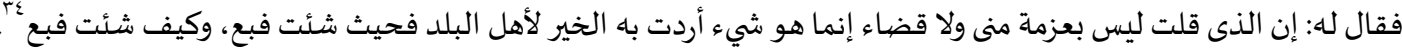

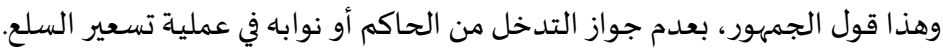

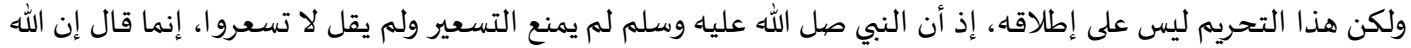

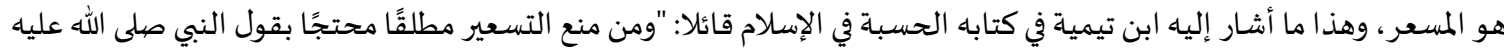

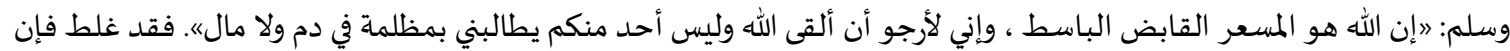

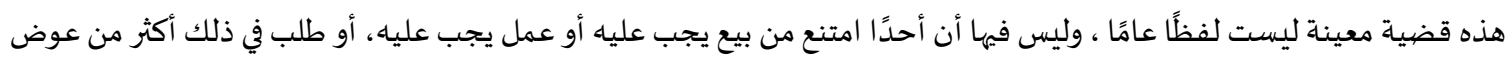

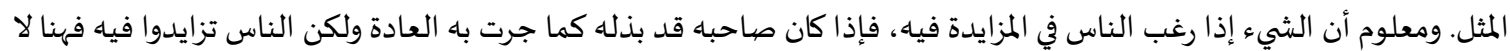

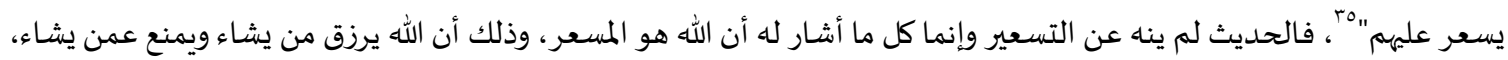
وذلك ما يؤثر في ثمن السلعة بكثرتها أو بندرتها.

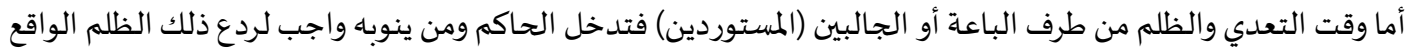

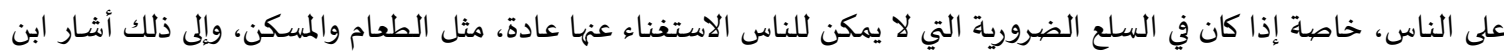

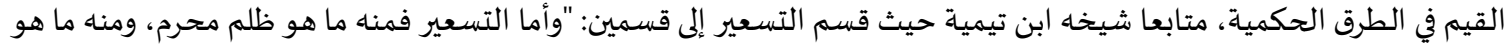

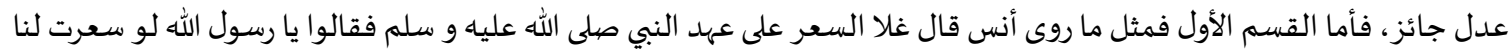

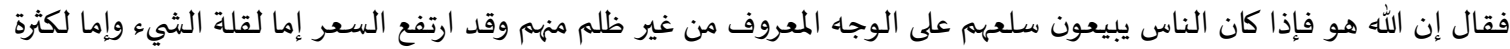

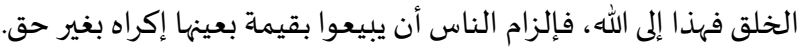

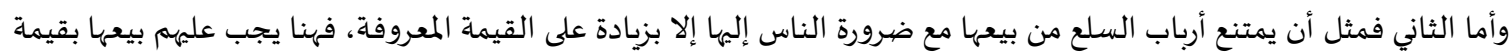

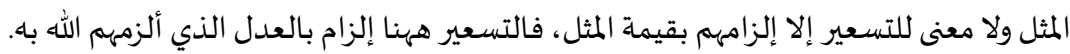

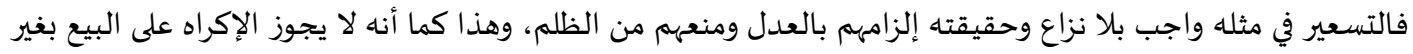

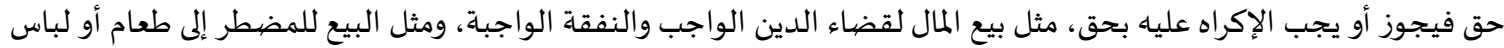

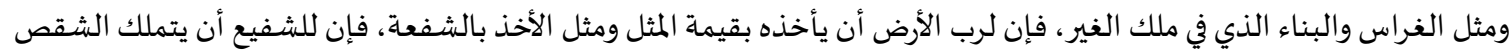

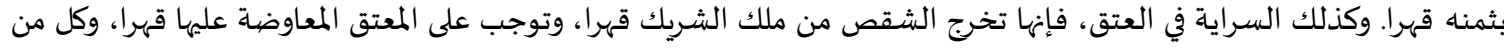

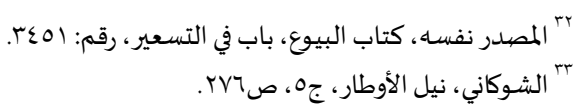

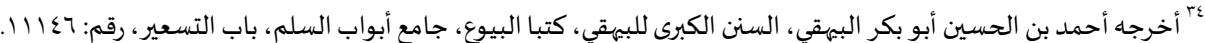

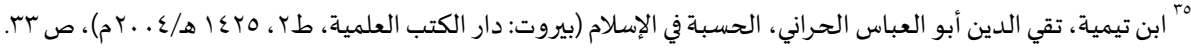


وجب عليه شيء من الطعام واللباس والرقيق والمركوب بحج أو كفارة أو نفقة، فمتى وجده بثمن المثل وجب عليه شراؤه، وأجبر على

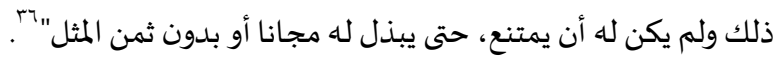

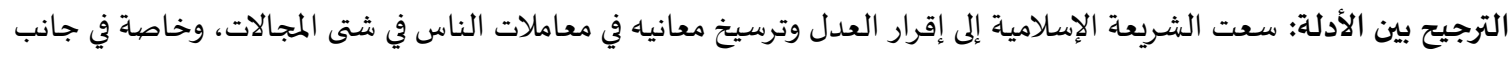

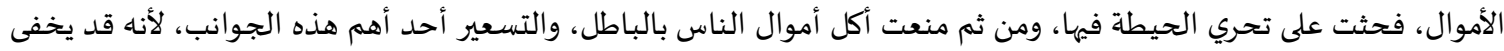

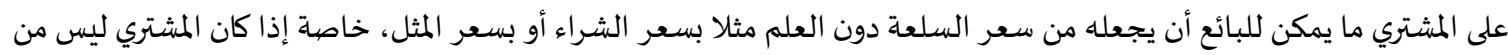
أهل السوق والخبرة في هكذا معاملات. ومن جهة أخرى لابد من التدخل لتسعير الحاجات الضرورية التي لا غنى للناس عنها، مثل الطعام والمسكن، فتدخُّل الحاكم أو نائبه

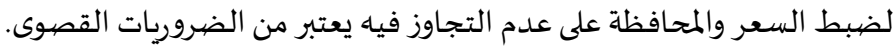

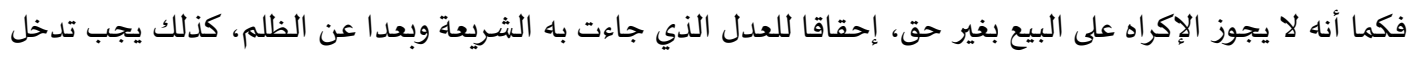

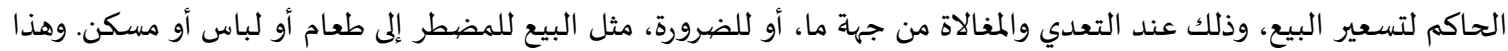

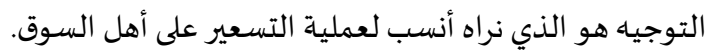

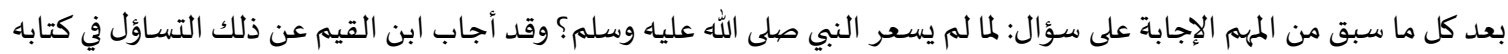

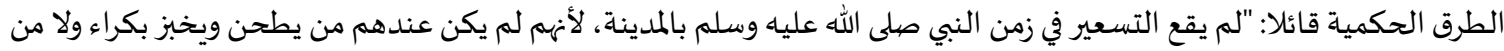

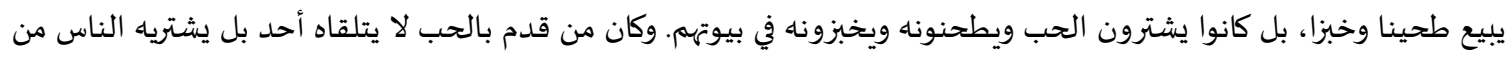

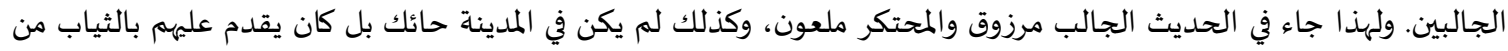

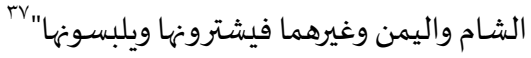

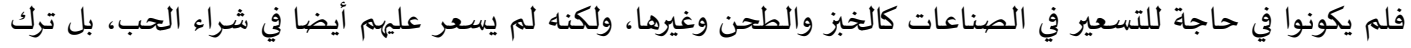

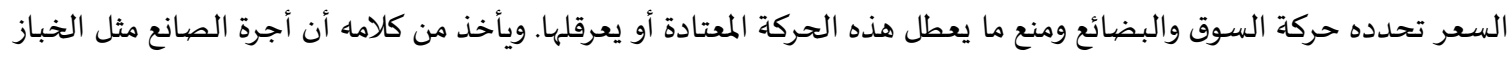

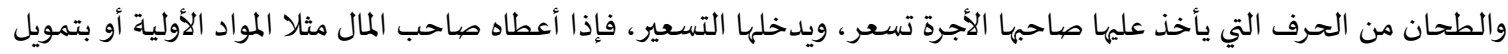

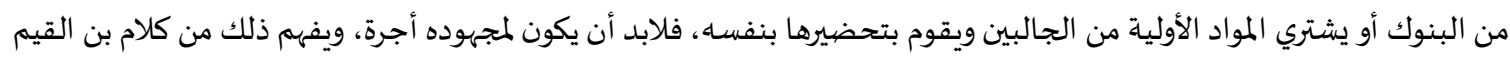

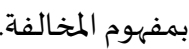
كما أن كل احتكار في السلع التمويلية محرم لأنه يؤدي إلى زيادة ثمنه، ومن ذلك الموادواد الأولية التي تستعمل في البناء، فلا يجوز

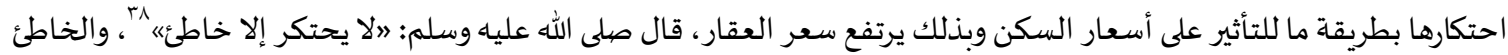

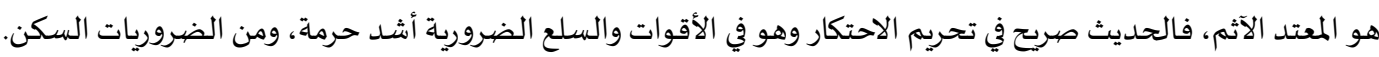

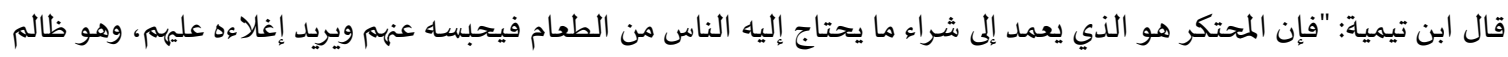

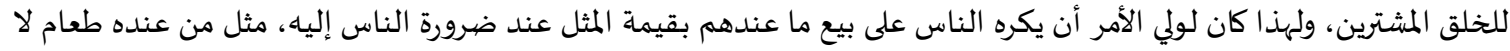

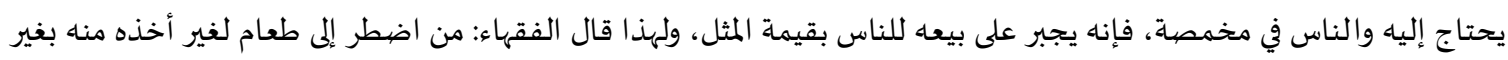

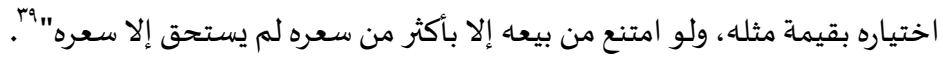

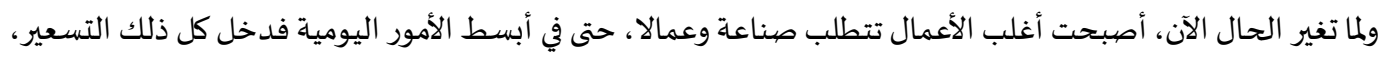
ولكن باختلاف الآليات والوسائل التي يتم بها التسعير.

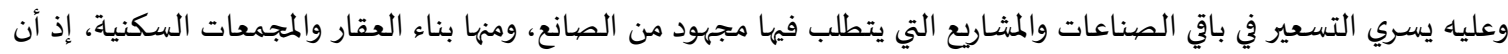

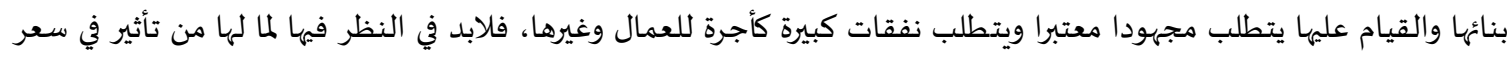

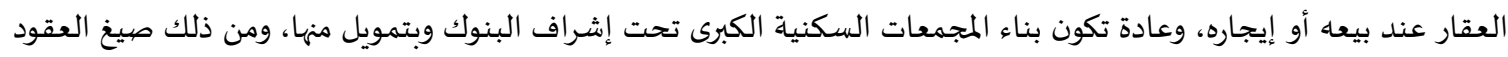

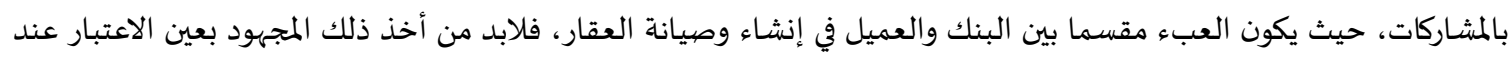
تحديد سعر بيع أو إيجار ذلك العقار.

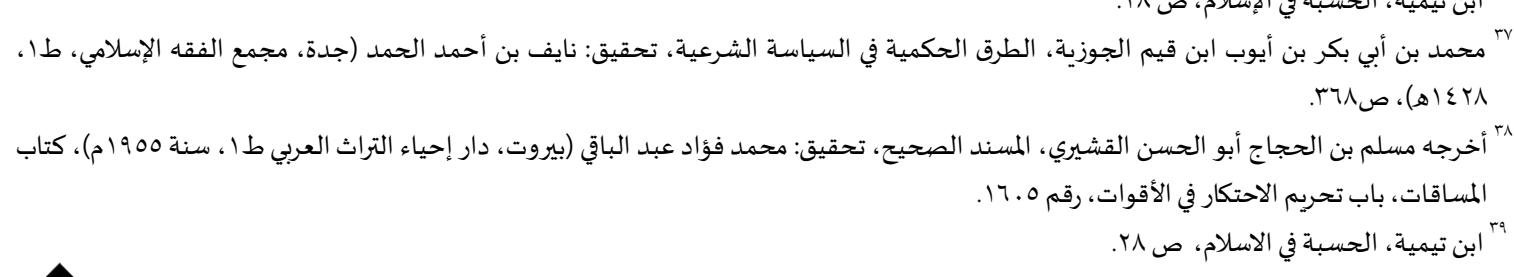

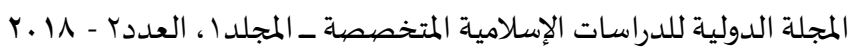




\section{المبحث الثاني: المعايير العامة للتسعيرفي الشريعة الإسلامية.}

المطلب الأول: ما يشمله التسعير.

تبعا لاختلاف الفقهاء في حكم التسعير بين مجيز ومانع، وبين مقيد ومطلق، اختلفوا في السلع والخدمات التي يجرى فيها

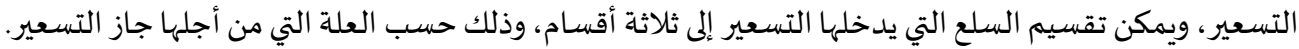

أولاً: التسعيرفي القوتين فقط ونم

ممن ذهب إلى ذلك ابن عابدين من الحنفية، وأن التسعير يجري في القوتين قال في الدر المحتار والحاشية: "وأفاد أن التسعير

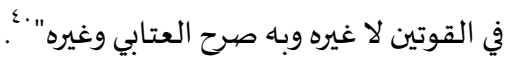

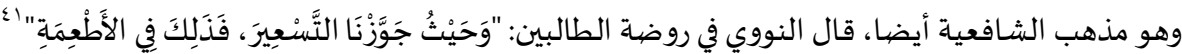
وقال في أسنى المطالب شرح روضة الطالب عند شرحه لحديث أنس في تحريم التسعير ، قال: "وقضية كلامه كالأصل إن ذلك الك

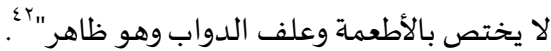

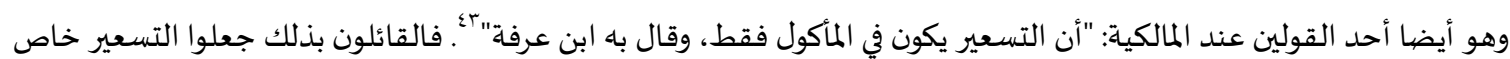
بالأطعمة والقوتين، قوت الإنسان وقوت الدواب. وذلك لعدم استغناء الناس عن أقواتهم وكذلك أقوات دوابهم التي يقضيون بها حاجاتهم ومشاغلهم، فلو خفض البائع سعر هذين السلعتين أو زاد فيسعر عليه ويجبر أن يبيع بالسعر الذي يحدده البائع. وجعلوا

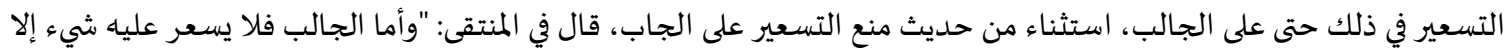

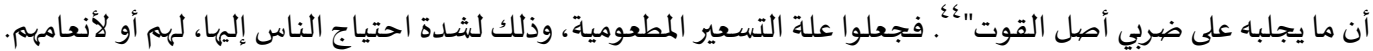

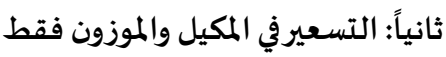
للمالكية قول ثان في المذهب بأن التسعير يكون في المكيل والموزون فقط، ونقل الباجي هذا القول عن ابن حبيب في باب ما يتعلق به التسعير من المبيعات قال: "قال ابن حبيب إن ذلك في المكيل والموزون مأكولا كان أو غير مأكول، دون غيره من المبيعات التي

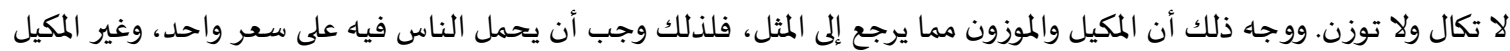

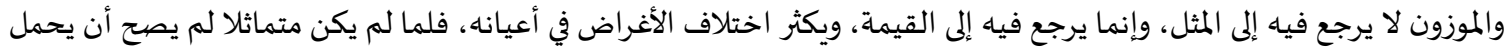

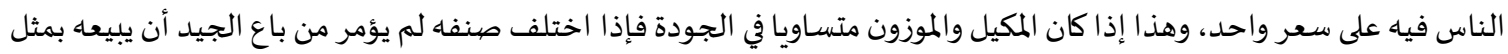

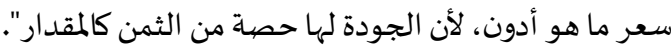
فعلة جواز التسعير عندهم توفر المثلية في السلعة، سواء كان قوتا أو غيره، ذلك أنهودة أنه يمكن معرفة المقدار الذي يتم تسعيره وإعطائه ثمنا معينا، فإذا كانت هذه السلعة تباع بدرهم لمقدار معين فيبيعها شخص ثاني بأكثر من درهم أو أقل سُعر عليهاه، لأن المقدار نفساه

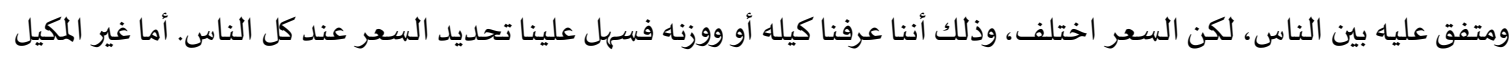

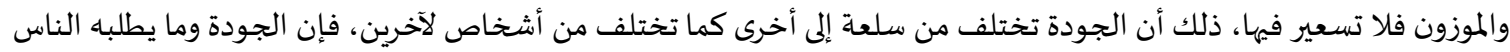

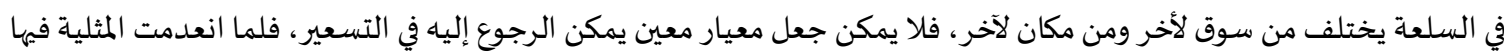

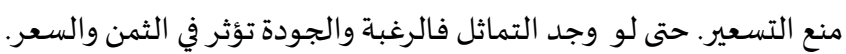

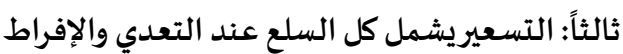

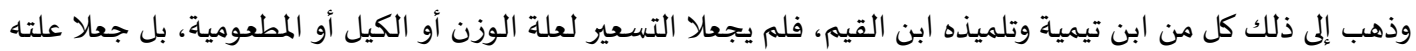

التعدي والإفراط.

قال ابن تيمية: "فإذا تضمن ظلم الناس وإكراههم بغير حق على البيع بثمن لا يرضونه أو منعهم مما أباح الله لهم فهو حرام،

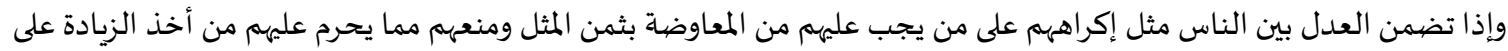

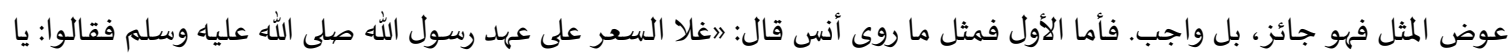

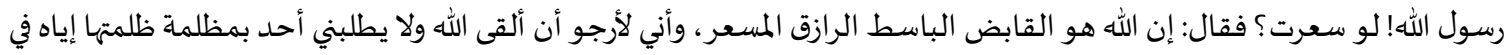

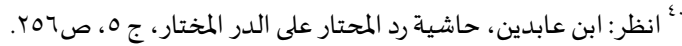

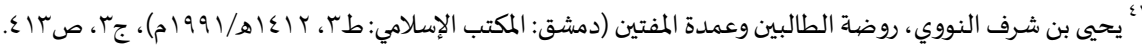

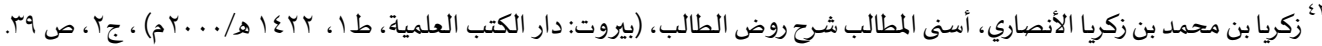

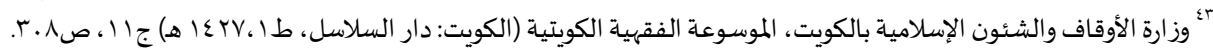

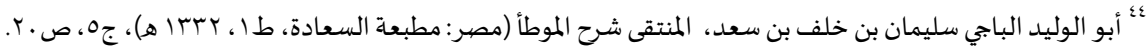

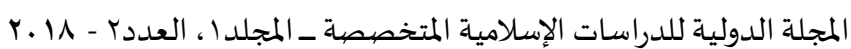


دم ولا مال، فإذا كان الناس يبيعون سلعههم على الوجه المعروف من غير ظلم منهم وقد ارتفع السعر إما لقلة الشيء، وإما لكثرة الخلق، فهذا إلى الله، فإلزام الخلق أن يبيعوا بقيمة بعينها إكراه بغير حق.

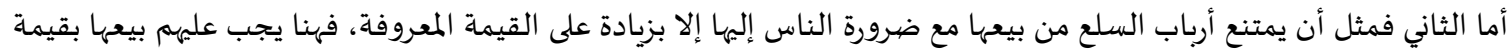

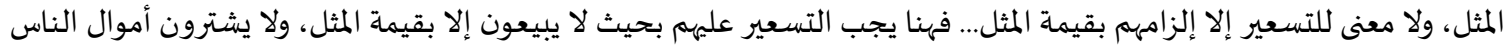

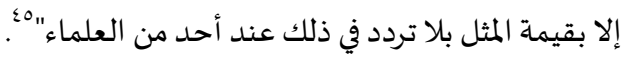
فجعل التسعير متعلقا بتعدي الباعة، فإذا كانت زيادة أو نقصان منهم أجبروا على البيع بسعر المثل، وذلك على ضربين،

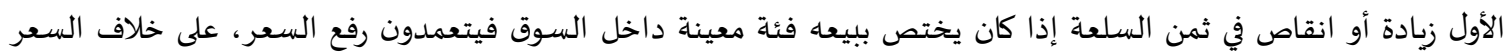
المتعارف عليه بين أهل السوق، والضرب الثاني هو الاحتكار منع السلعة من التداول، فيرتفع سعرها لندرتها وكثرة الطلب عليها.

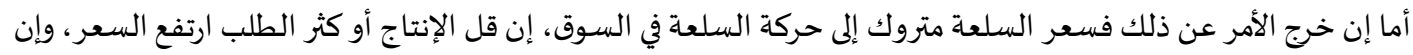

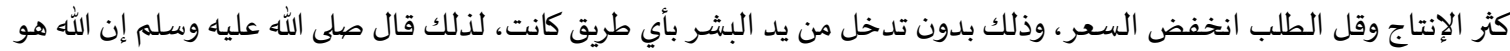

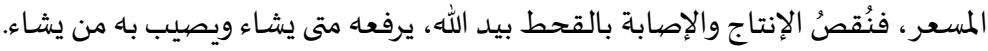

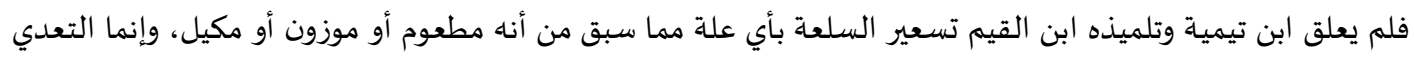

والإفراط هو العلة، وعلى ذلك يدخل التسعير في كل السلع المتداولة في السوق سواء كانت منقولا أو عقارا أو مطعوما أو موزونا.

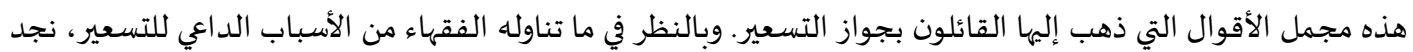
أن أهمها هو النظر في حاجيات الناس منع الجور والتعدي من الباعة، وعلى ذلك ننظر في المنتجات المالية في البنوك الإسلامية هل

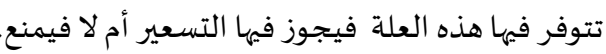
أما علة المطعومية التي اتخذت كعلة لجواز التسعير، فمن باب عدم الاستغناء عنها من طرف الناس، وضروريتها للحياة،

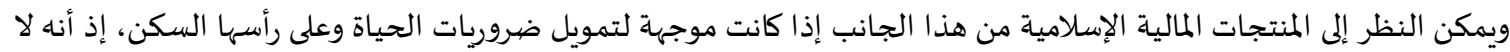
غنى لكل شخص عنهه، فيلجأ للتسعير إذا تحققت هذه الضرورة وخاصة في حالة أزمة السكن وارتفاع أسعار العقار.

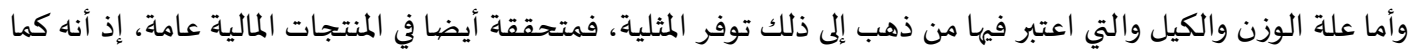
سبق ذكره تعتبر النقود الأساس في تحديد قيمة السلع، ومادامت المنتجات المصرفية أساسها نقود فالمثلية متحققة.

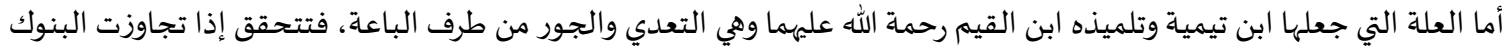

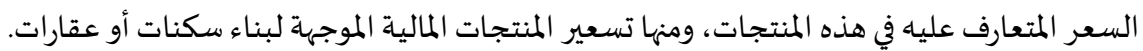
وتسعير إيجار العقارات قد يصل تدخل الحاكم أو من ينوبه إلى درجة الوجوب، لأها تعتبر أحد أهم الضروريات التي لا

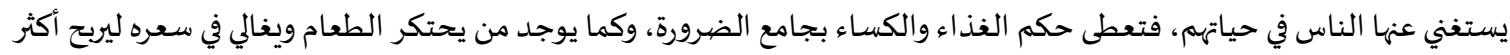

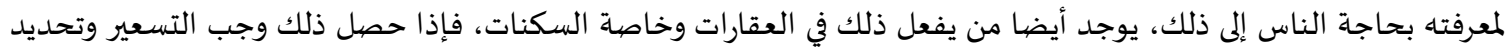

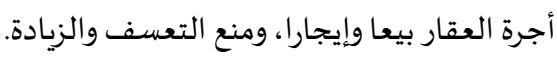
وتحديد أجرة العقار تكون على حسب المنافع التي يرجى الحصول عليها من تلك العقارات، فليس كل العقارات من ضروريات

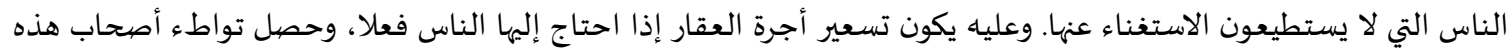

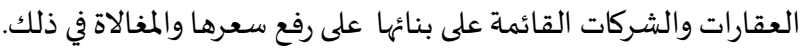

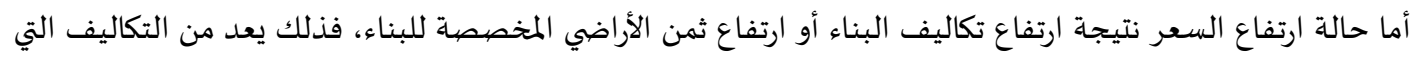

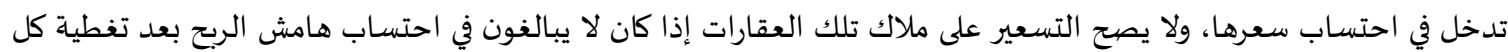
التكاليف الأخرى.

المطلب الثاني: المعايير الشرعية العامة في التسعير في تعريفهم للبيع قال المالكياة: "هو عقد معاوضية على غير منافع ولا متعة لذة. ذو مكايسة، أحد عوضياه غير ذهب ولا فضا فضية،

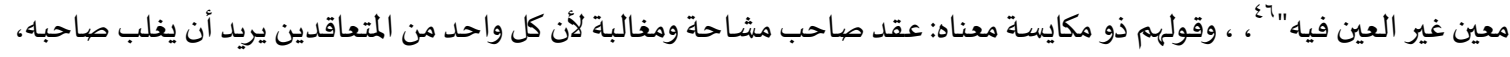

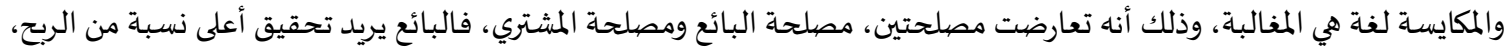

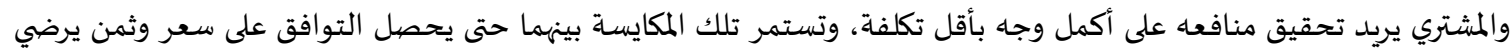

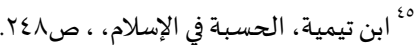

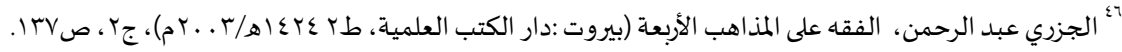

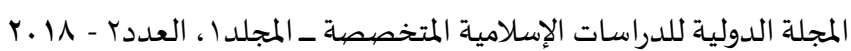


الجانبين ويتم إمضاء العقد، لكن في أحوال أخرى تؤثر عوامل على هذا التوافق والتراضي بين الطرفين، منها الجشع وحب الريح

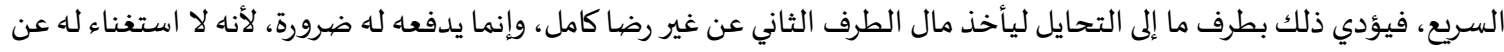

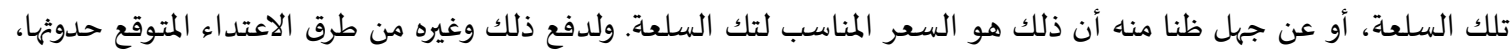
جعلت الشريعة الإسلامية صمامات أمان لابد من الالتزام بها في المعاملات تحقيقا للعدل ودفعا للظلم واجتنابا للضرر. ونتطرق فيما

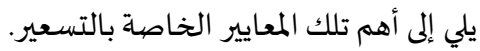

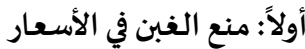

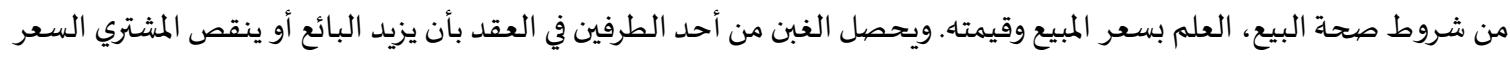

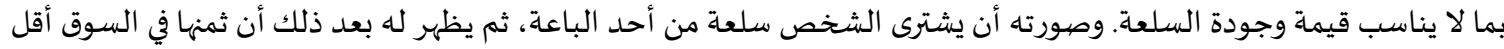

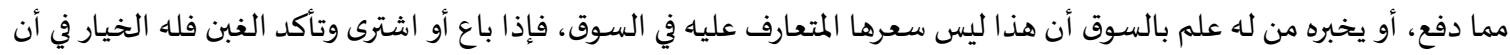
يرجع في عقده وفسخها. وذلك إن وقع غبن على من لا معرفة له بسعر السوق والبيع والشراء، قال النووي في المجمموع عند كلامه عن خيار الغبن في البيع: "يكره

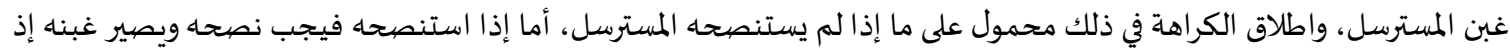

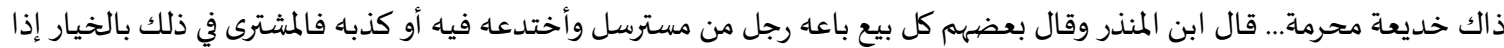

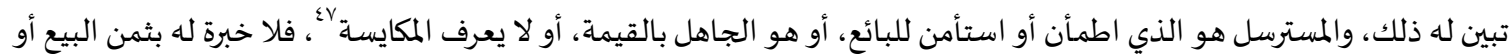
جودة السلعة. ومن ذلك ما ورد عن ابن عمر رضي الله عنهما، قال: ذكر رجل لرسول الله صلى الله عليه وسلم أنه يخدع في البيوع، فقال :

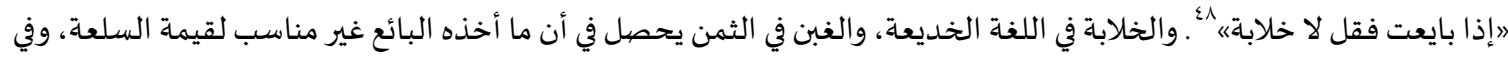

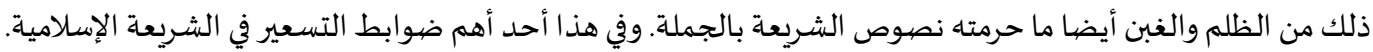

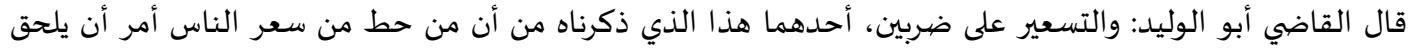

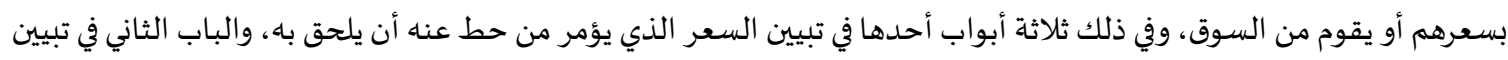

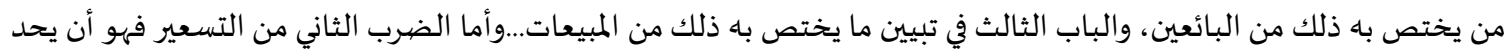

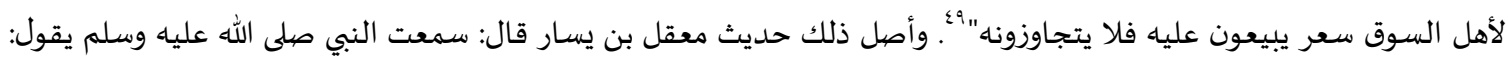

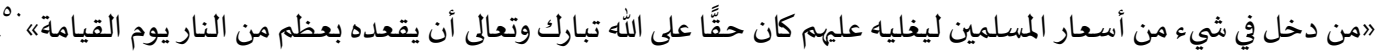

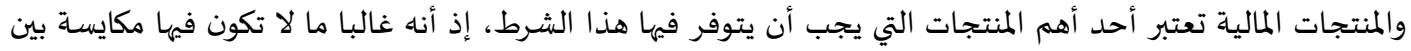

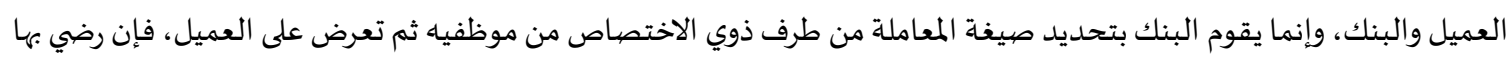

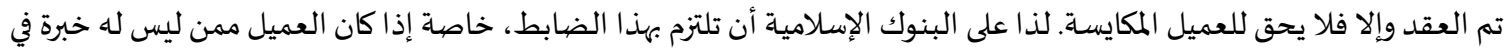

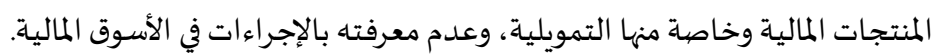
ثانياً: عدم المغالاة والفحش في أخذ الريح

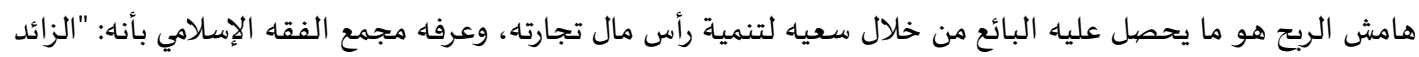

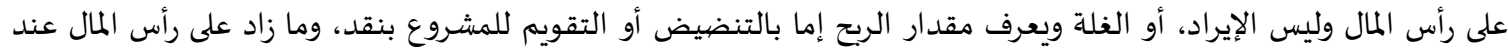

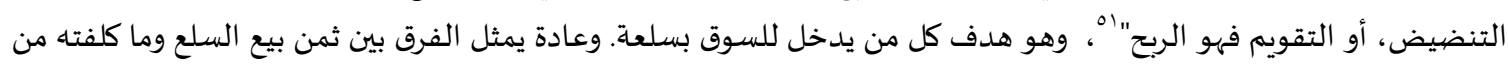

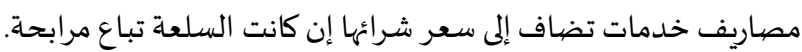

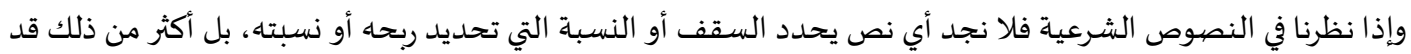
ورد في السنة التقريرية ما يُجوز بلوغ الريح نفس قيمة السلعة، وذلك في قصة عروة البارقي، أن النبي صلى الله عليه أعطاه دينارا

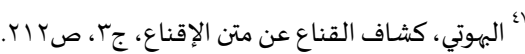

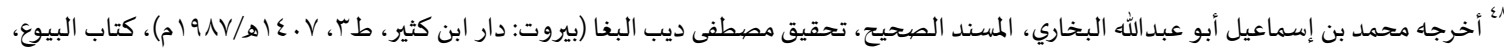

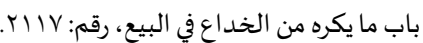

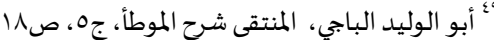

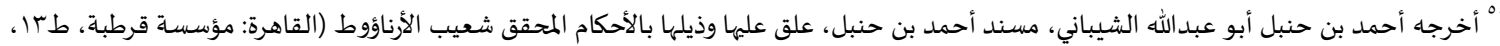

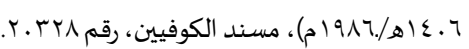

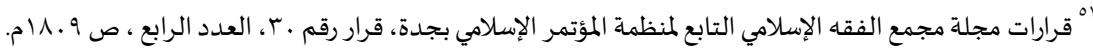


يشتري له شاة للضحية، فاشترى له شاتين، فباع إحداهما بدينار، فأتى النبي صلى الله عليه بشاة ودينار، فدعا له النبي صلى الله عليه

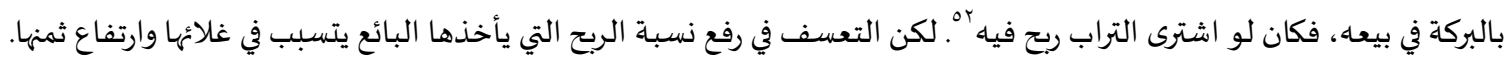

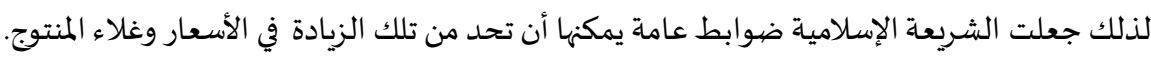

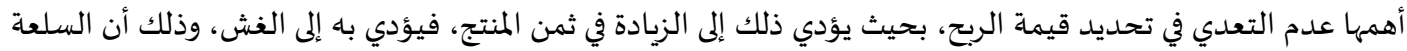

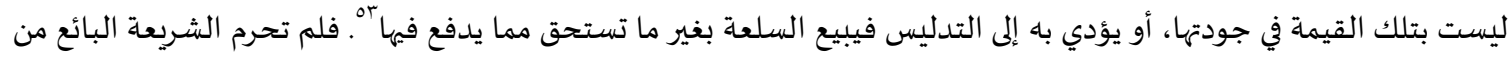

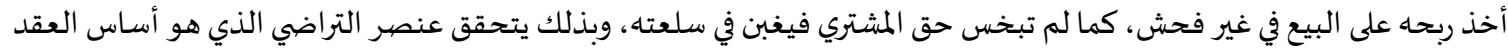

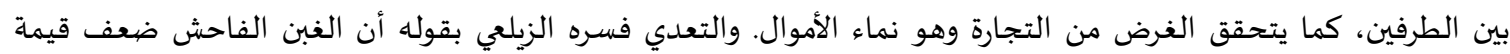
السلعة "، كأن يشترهها بعشرة ويبيعها بعشرين.

أما كيفية تحقيق ذلك، فيكون بمراعات قيمة السلعة عند الشراء ثم تقدير الجههد، ويقدر السعر على حساب ذلك، "فلا لإنا

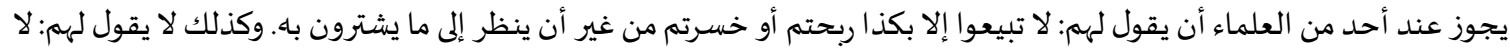

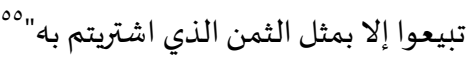

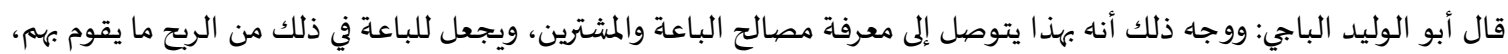

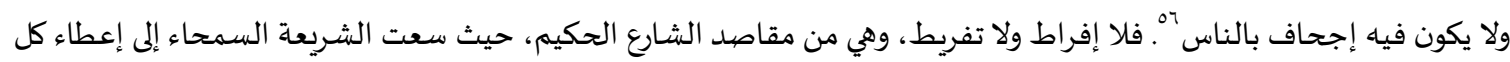
ذي حق حقاه، دون تعدٍ على حقوق الآخرين.

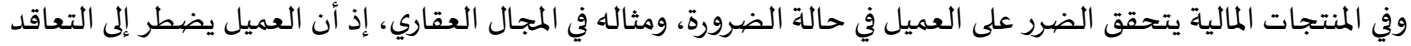

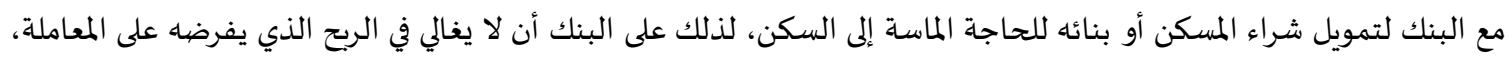

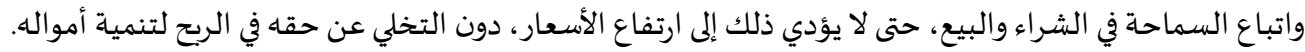

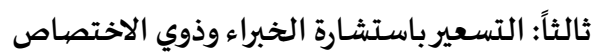

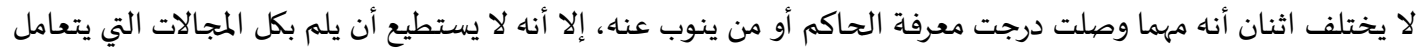

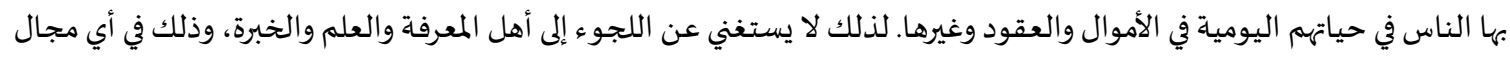

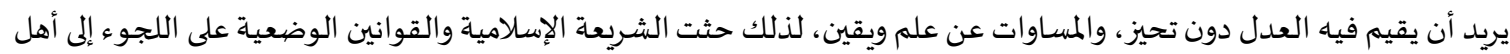

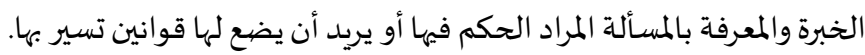

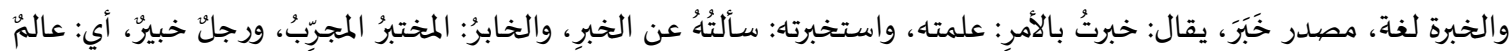

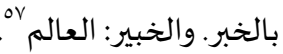
وتعريفها لغة مناسب للتعريف الاصطلاحي بأها العلم بالشيء، ومن ذلك أنها: "وسيلة إثبات علمية، يقوم بها أهل العلم والاختصاص،

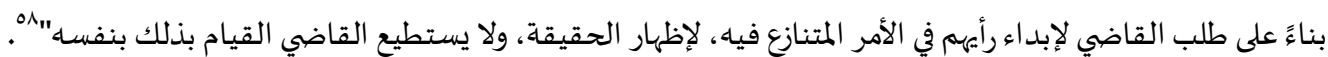

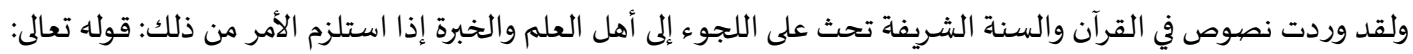

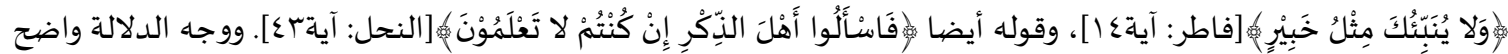

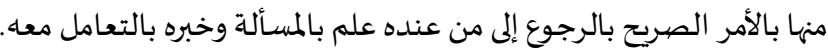

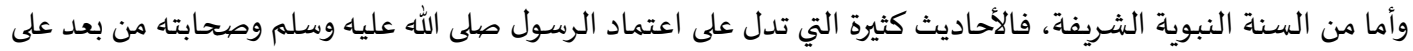
أهل القافة، وهم أهل المعرفة والخبرة ومنها ما أخرجاه مسلم في صحيحها: من حديث من قتلوا النيا راعي إبل الصدقة واستاقوا الإبل،

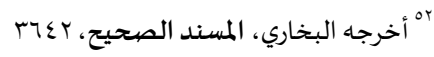

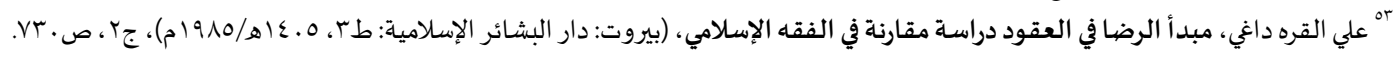

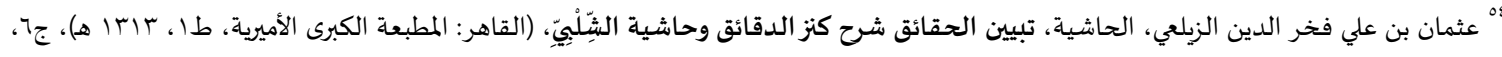

صV ص

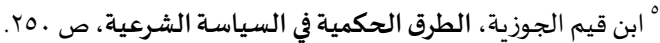

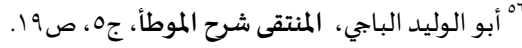

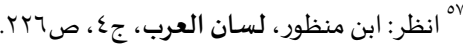

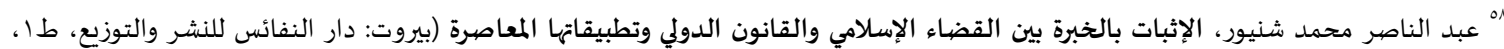

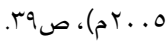


فأرسل شبابا من الأنصار قريب وأرسلهم إلههم وبعث معهم قائفا يقتص أثرهم ". فأرسل الرسول صلى الله عليه وسلم من له خبرة بأثر

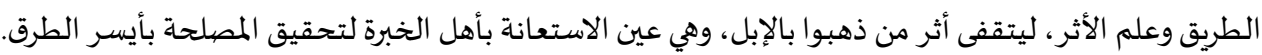

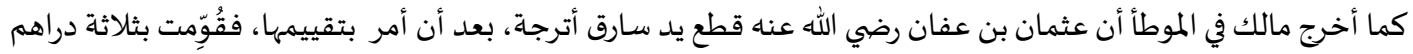

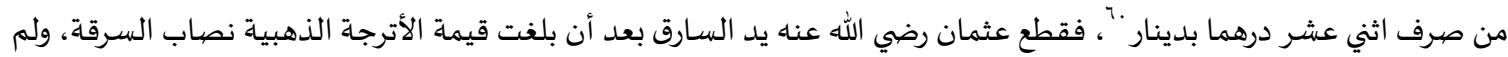

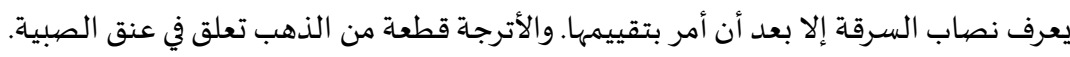

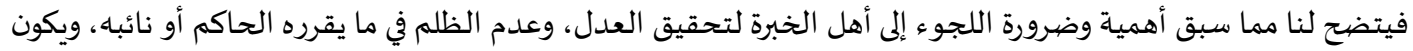

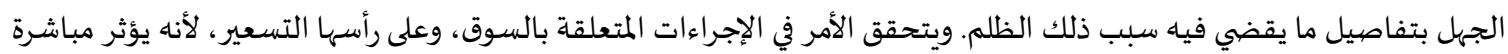

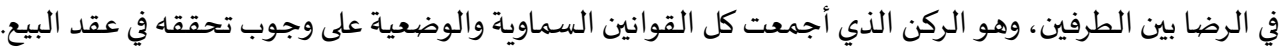

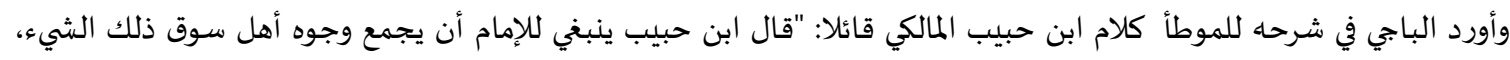

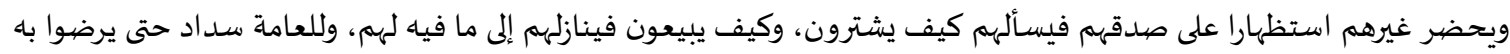

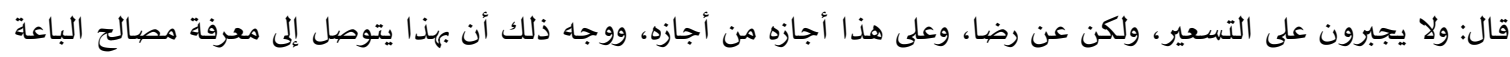

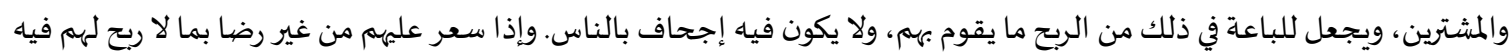

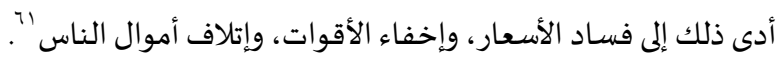

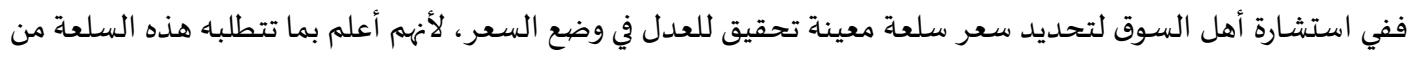

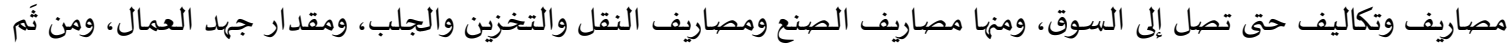

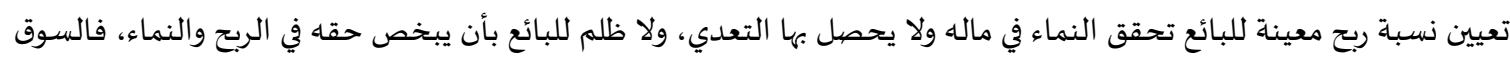

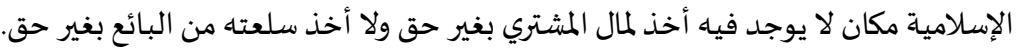

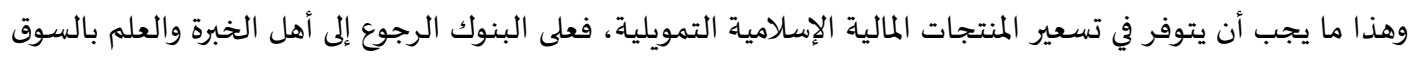

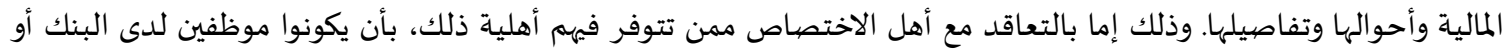

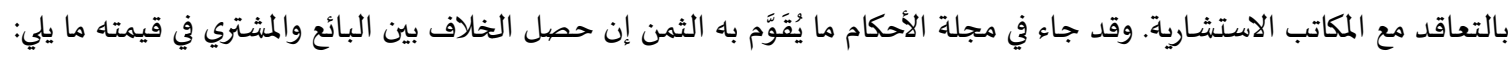

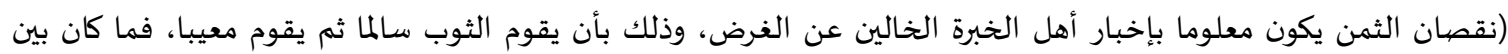

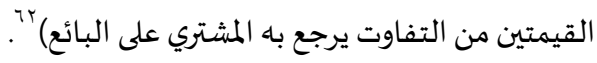

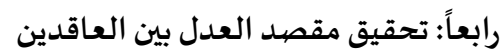

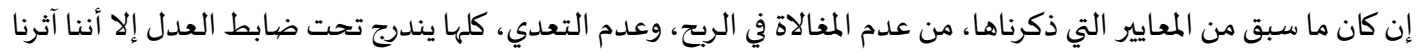

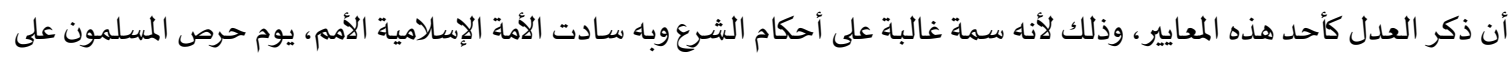

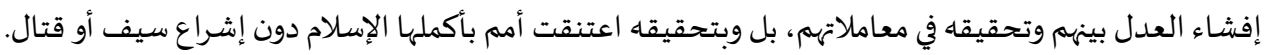

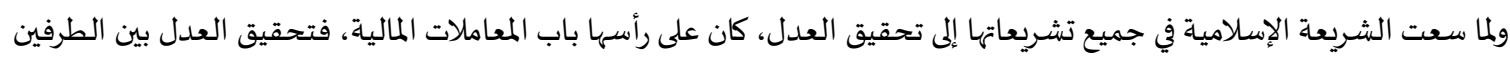
يكون بجعل الثمن والسلعة بنفس القيمة أو بقيمة متقاربة بينهما.

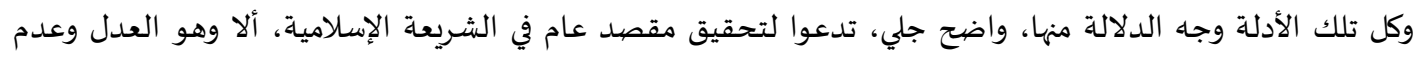

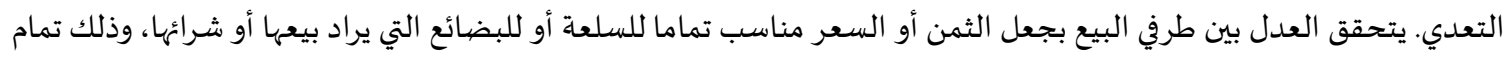

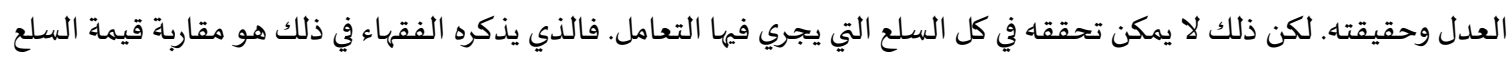

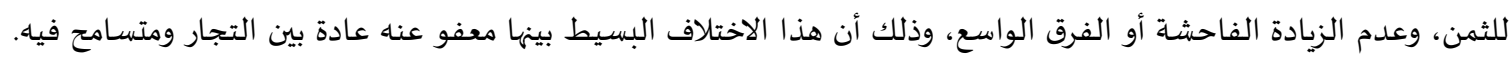

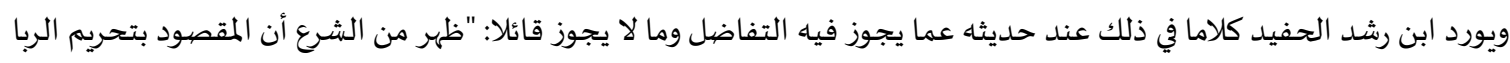

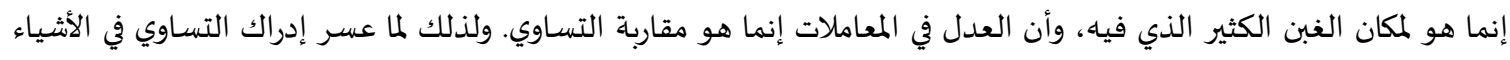

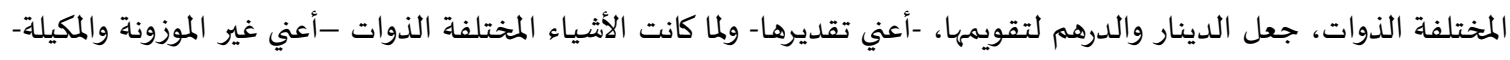

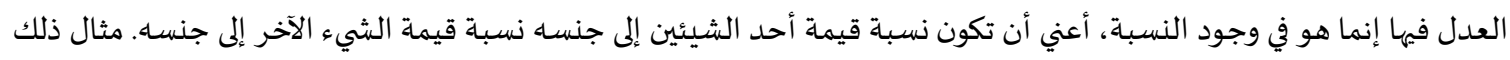

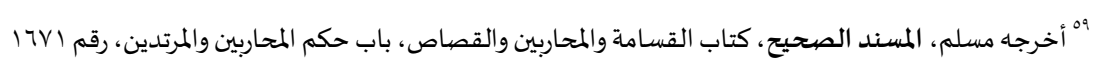

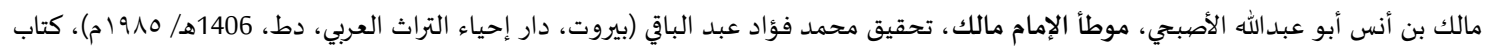

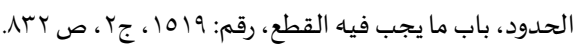

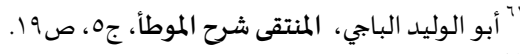

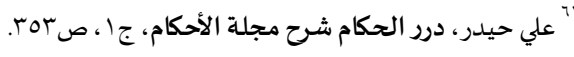


أن العدل إذا باع إنسان فرسا بثياب، هو أن تكون نسبة قيمة ذلك الفرس إلى الأفراس هي نسبة قيمة ذلك الثوب إلى الثياب، فإن كان

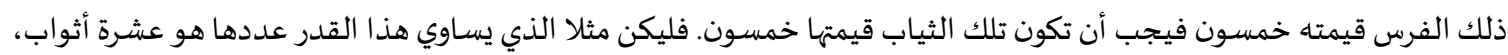

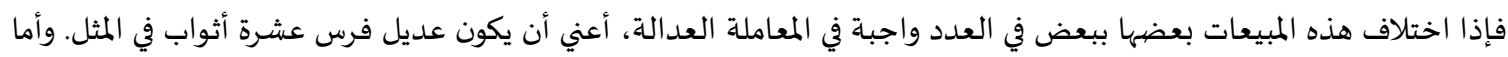

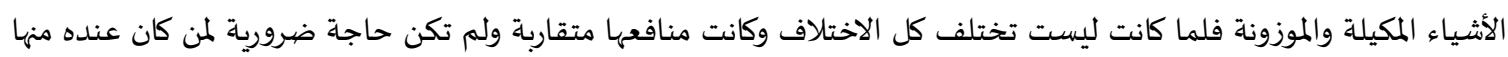

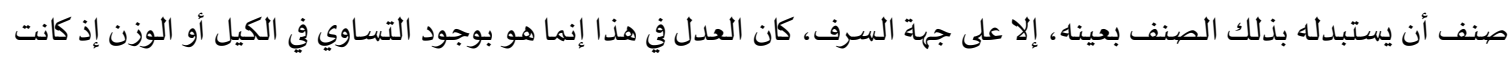

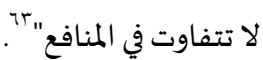
فأشار إلى أن الغبن الكثير هو الذي يمنع إنفاذ العقد، وأن العدل في المعاملات يقصد به التقارب في التساوي، فالاختلاف

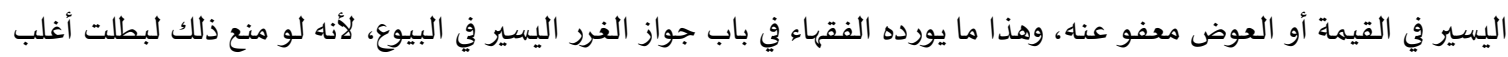

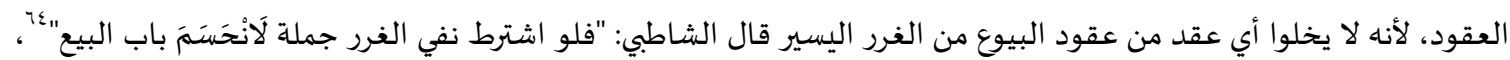

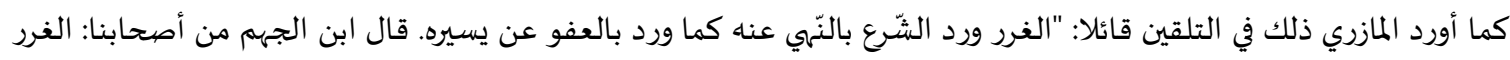

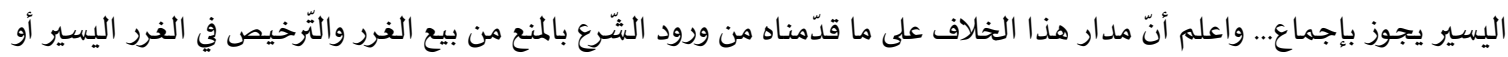

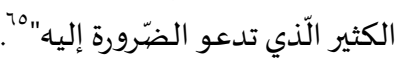
فجعل المازري العفو عن الغرر مضبوطا بقيدين هما: اليسر في نسبته وأن يكون غير مقصودا بل عرضا. والثاني أن يكون مما تدعوا إليه الضرورة.

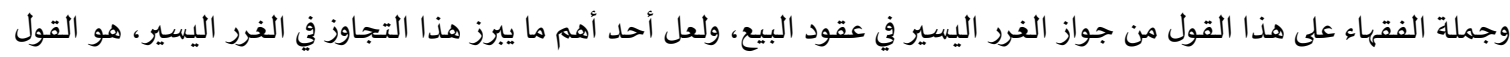

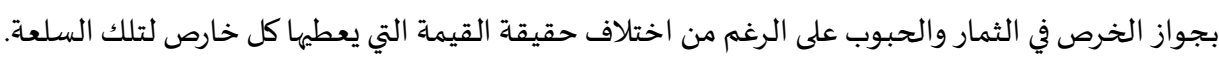

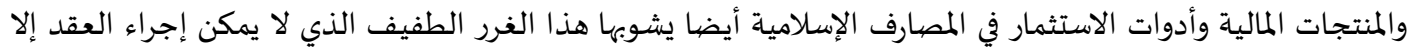

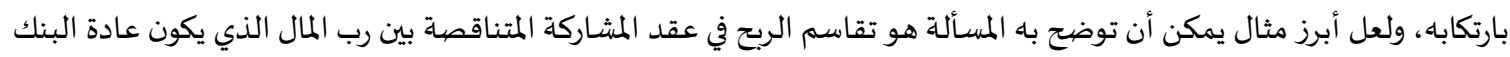

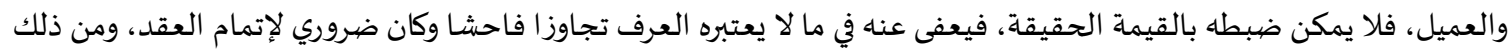

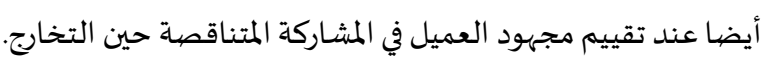

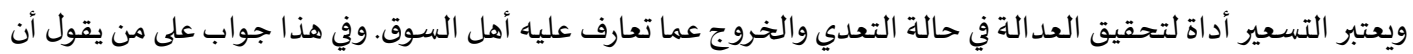

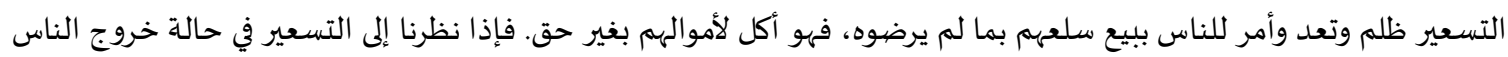

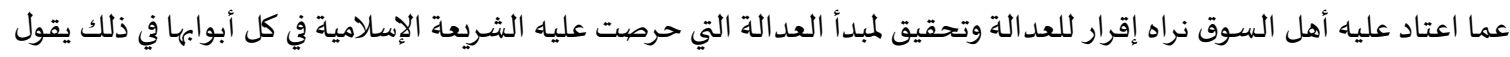

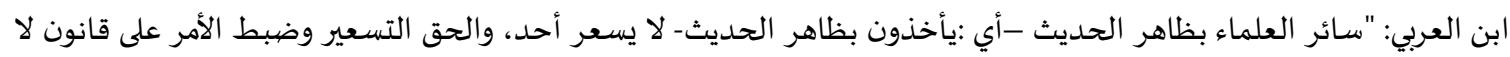

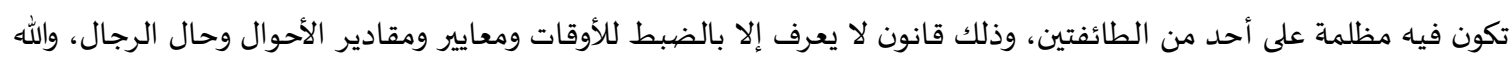

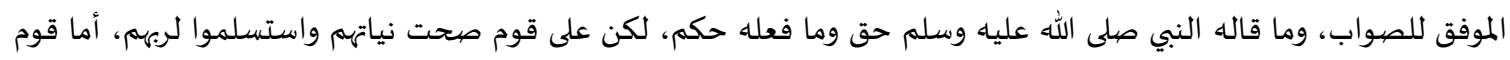

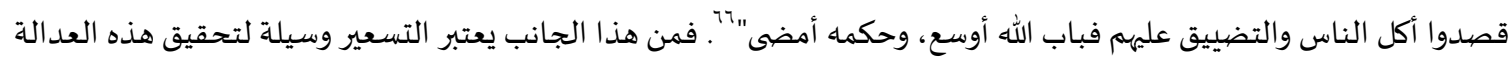

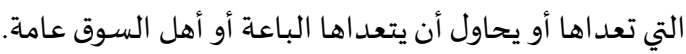

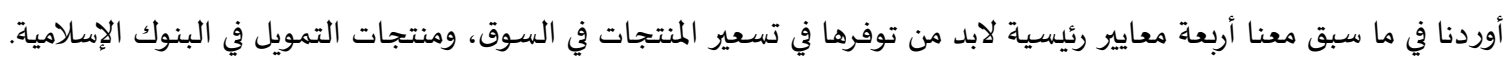

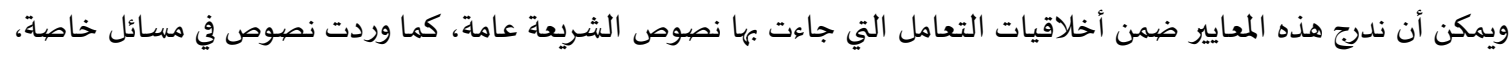

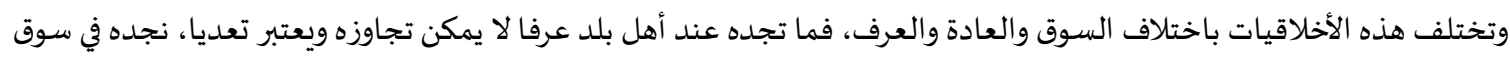
أخرى يُتعامل له ولا يؤثر في العقد ولا يترتب عليه أي نتيجة.

الخاتمة

التسعير في الاقتصاد الإسلامي يتمحور حول عدة محاور أخلاقية أهمها: الصدق والأمانة، تحريم الغش والخداع، منع الربا

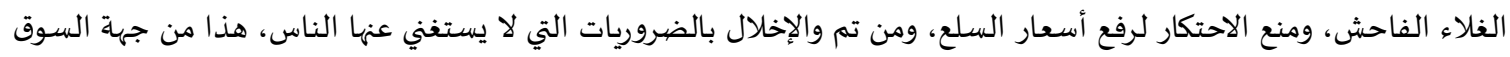

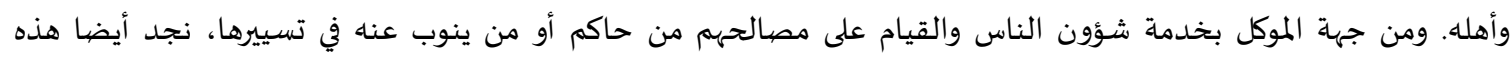

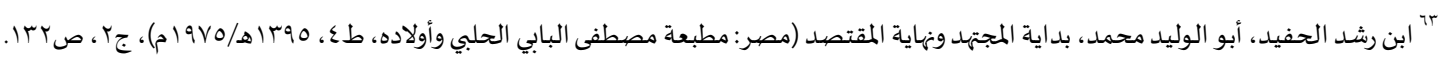

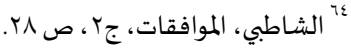

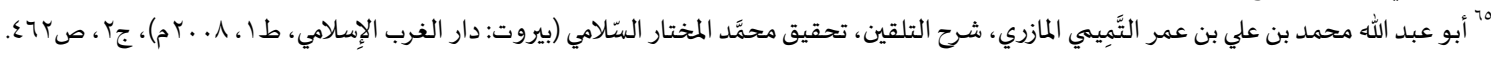

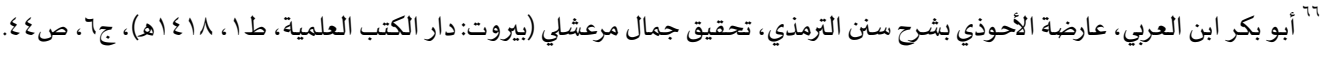


الأخلاقيات كأحد الأسس التي لا يستغنى عنها، كالإضرار بمصالح الباعة وتحديد ربحهم وعوائد تجارتهم، أو الضرر بتعاملاتهم عند الغلاء إذا لهم يكن لهم دخل في ذلك.

النتائج:

ا. . سعت الشريعة الإسلامية إلى إقرار العدل وترسيخ معانياه في معاملات الناس في شتى المجالات، وخاصة في جانب الأموال. r. يسري التسعير في الصناعات والمشاريع التي يتطلب فهها مجهود من الصانع، ومنها بناء العقار والمجمعات السكنياة، إذ أن بنائها والقيام عليها يتطلب مجهودا معتبرا ويتطلب نفقات كبيرة كأجرة للعمال وغيرها، فلابد في النظر فيها لما لها من تأثير في سعر ونياء العقار عند بيعها أو إيجاره

r. آلية سعر السـوق تعتبر أهم الآليات المعتمدة في التسعير في الشريعة الإسلامية، لأنه لا خلاف فيها بين جمهور الفقهاء.

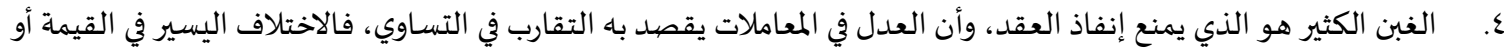
العوض معفو عنه

0. العفو عن الغرر مضبوطا بقيدين هما: اليسر في نسبته وأن يكون غير مقصودا بل عرضا، والثاني أن يكون مما تدعوا إليه الضرورة. التوصيات:

يجب تدخل الحاكم أو من ينوبه في تسعير إيجار وبيع العقارات إذا غلا السعر، لأها تعتبر أحد أهم الضروريات التي لا يستغني

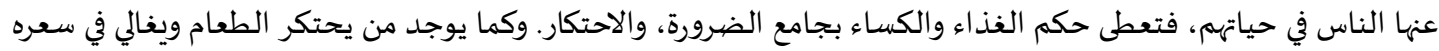

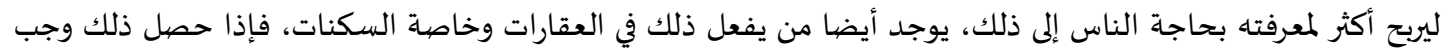

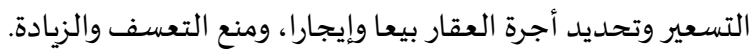

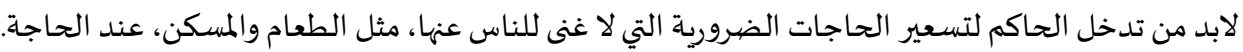
تحديد أجرة العقار تكون على حسب المنافع التي يربى الحصول عليها من تلك العقارات، فليس كل العقارات من ضروريات الناس التي لا يستطيعون الاستغناء عنها.

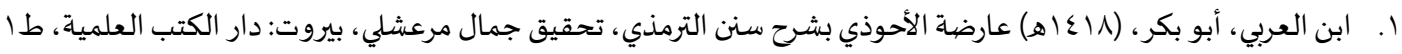

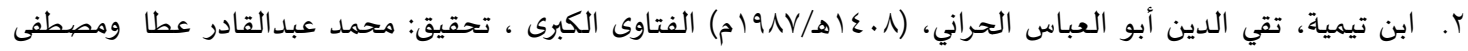

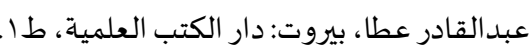

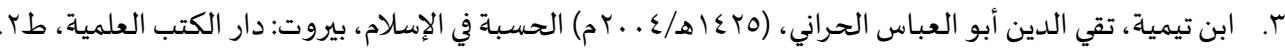

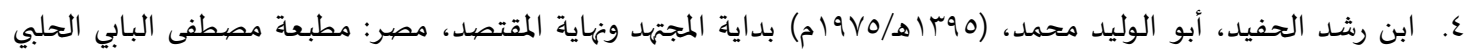
وأولاده، طع.

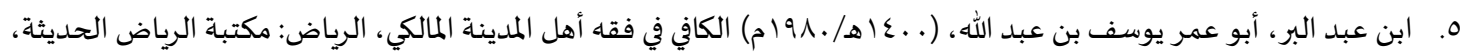
ط.

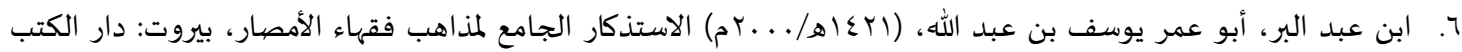

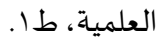

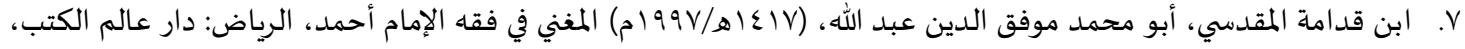
طr.

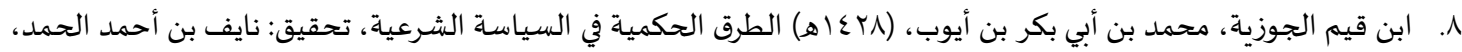

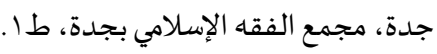

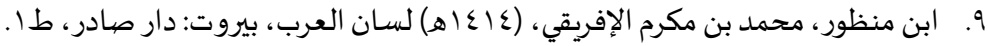

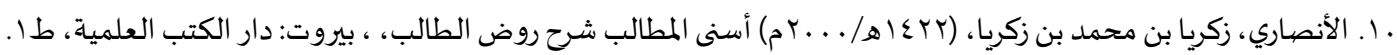

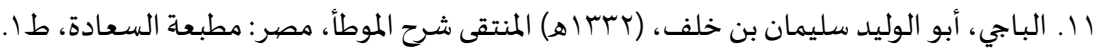

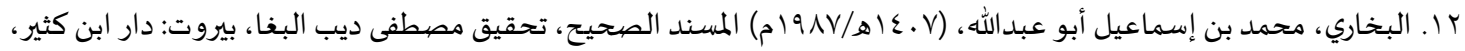




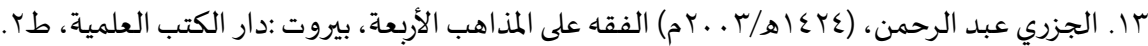

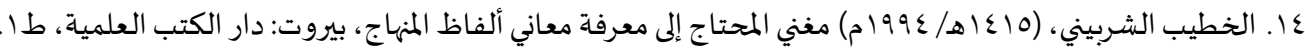

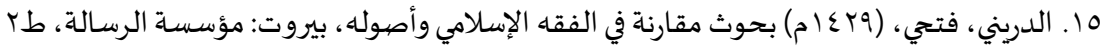

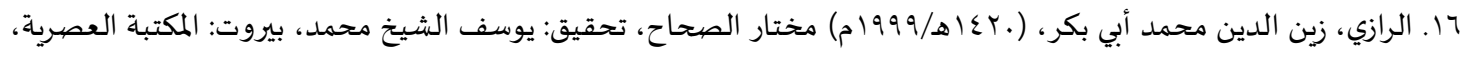

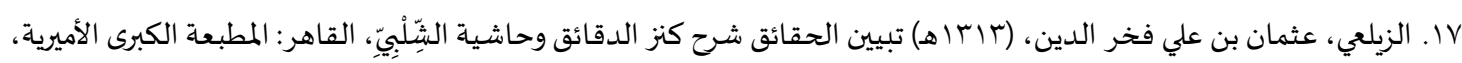

11. السيوطي، مصطفى بن عبده، (1971 م) مطالب أولي النهى في شرح غاية المنتهى، دمشق: المكتب الإسلامي.

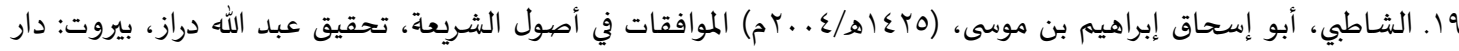
المعرفة، طا.

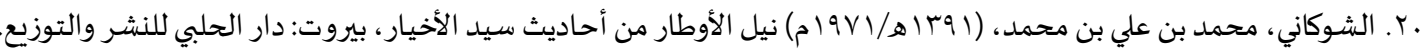

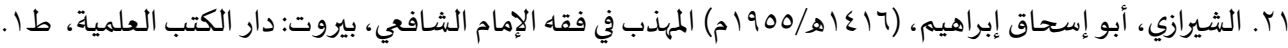

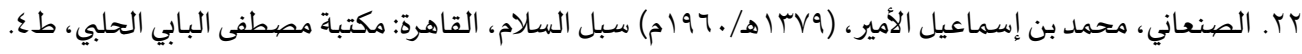

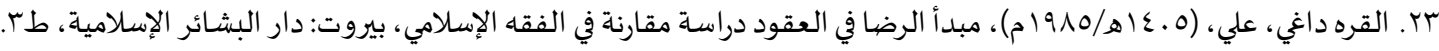

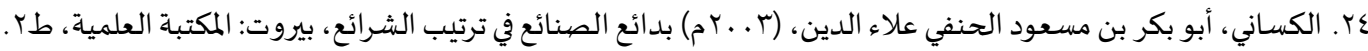

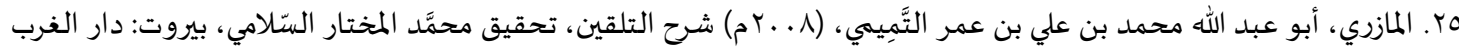

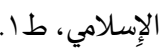

جr. المجليدي، القاضي أحمد بن سعيد، (دت) التيسير في أحكام التسعير، الجزائر: الشركة الوطنية للنشر والتوزيع، طا

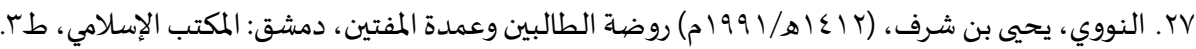

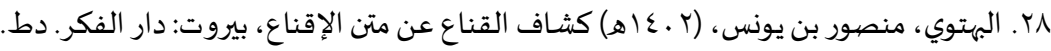

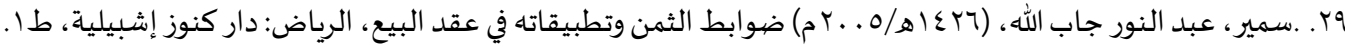
•r. سيد، هواري، (r (919 م) الموسوعة العلمية والعملية للبنوك الإسلامية والاستثمار، مكة المكرمة: الاتحاد الدولي للبنوك الإسلامية.

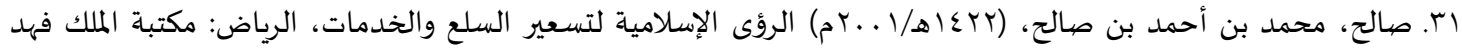
الوطنية، طا. r r. عبد الناصر، محمد شنيور، (0 . Fم) الإثبات بالخبرة بين القضياء الإسلامي والقانون الدولي وتطبيقاتها المعاصرة، بيروت: دار

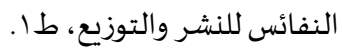

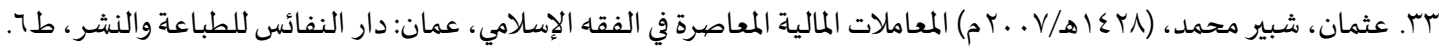

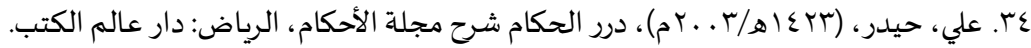

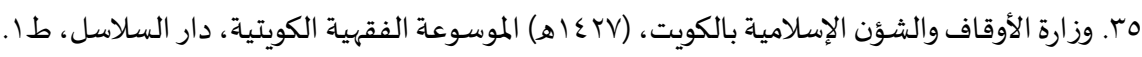

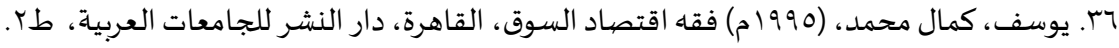




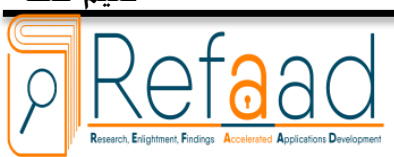

رفاد للدراسات والأبحاث

www.refaad.com

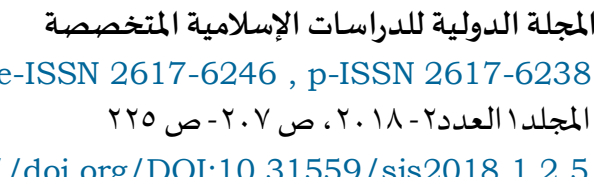

https://doi.org/DOI:10.31559/sis2018.1.2.5

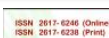

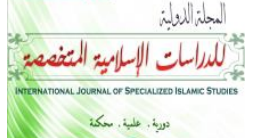

\title{
The General Pricing Mechanisms at the Islamic Market
}

\author{
Hank Naim \\ International Islamic University- The Kulliyyah of Islamic Revealed Knowledge \\ The Department of Fiqh and Usul al-Fiqh- Malaysia \\ naim.hank@gmail.com
}

\begin{abstract}
This study addresses the pricing of Islamic products and their mechanisms. The study aims to identify the applied pricing mechanisms in Islamic products and the general rules for its pricing

The paper reviews this development pricing mechanisms using arguments advanced by four major schools of Islamic jurisprudence. This study used the inductive approach to get the views of Islamic scholars on the pricing process. Besides, it used the analytical approach to identify the Islamic views on the pricing mechanisms. The results of this study indicate that the Muslim marketer needs to ensure that in the process of marketing, several elements must be considered and one of the most important elements that is worth giving attention to is pricing decision.
\end{abstract}

Keywords: pricing, pricing mechanisms, Islamic products.

\section{References:}

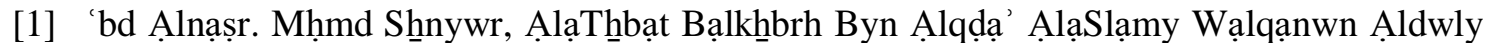
Wtṭbyqạthạ Ạlm 'ạṣrt, Byrwt: Dạr Ạlnfậys Llnshrr Wạltwzy', Ṭ1, (2005m)

[2] ly, Hydr, Dr Ạlḥkạm Sḥrḥ Mjlt Ạlạ̉ḥkạm, Ạlryạḍ: Dạr 'ạlm Ạlktb, (1423h-2003m)

[3] 'tḥmạn. Sḥbyr Mḥmd, Ạlm'ạmlạt Ạlmạlyh Ạlm'ạșrh Fy Ạlfqh Ạlạslạmy, 'mạn: Dạr Ạlnfạys Llțbạ h Wạlnshrọ, Ṭ6, (1428h-2007m)

[4] Ạbn 'bd Ạlbr. Ạ̉bw 'mr Ywsf Bn 'bd Ạllh, Ạlạstdhkạ̣ Ạljạm' Lmdhạhb Fqhạ' Ạlạ̉mșạr, Byrwt: Dạr Ạlktb Ạl'lmyh, Ț1, (1421h-2000m)

[5] Ạbn 'bd Allbr, Ạbw 'mr Ywsf Bn 'bd Ạllh, Ạlkạfy Fy Fqh Ạ̉hl Ạlmdynẗ Ạlmạlky, Ạlryạd: Mktbë Ạlryạd Ạlḥdythhh, Ṭ2, (1400h-1980m)

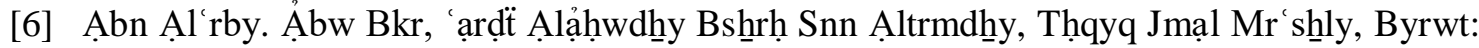
Dạr Ạlktb Ạl'lmyh, Ṭ1,(1418h)

[7] Ạbn Mnẓwr. Mḥmd Bn Mkrm ẠlạFryqy, Lsạn Ạl'rb, Byrwt: Dạr Ṣạdr, Ṭ1,(1414h)

[8] Ábn Qdạmh Ạlmqdsy. Ạ̉bw Mḥmd Mwfq Ạldyn 'bd Ạllh, Ạlmghnny Fy Fqh ẠlạMạm Ạhmd, Ạlryạḍ: Dạr 'ạlm Ạlktb, Ṭ3, (1417h-1997m)

[9] Ạbn Qym Ạljwzyh. Mḥmd Bn Ạ̉by Bkr Bn Ạ̉ywb, Ạlțrq Ạlḥmmyh Fy Ạlsyạsh Ạlsh̆r yh, Tḥqyq: Nạyf Bn Ạhmộ Ạlḥmd, Jdh, Mjm` Ạlfqh Ạlạslạmy Bjdh, Ṭ1, (1428h) 


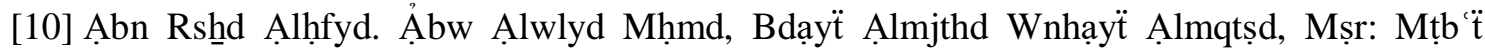
Mșṭa Ạlbạby Ạlḥlby Wạ̉wlạdh, Ț4,(1395h-1975m)

[11] Ạbn Tymyh. Tqy Ạldyn Ạ̉bw Ạl'bạs Ạlḥrạny, Ạlftạwy Ạlkbry, Tḥqyq: Mḥmd 'bdạlqạdr

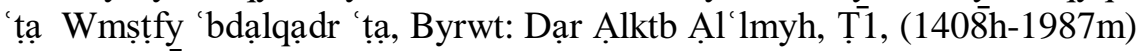

[12] Ạbn Tymyh. Tqy Ạldyn Ạ̉bw Ạl'bạs Ạlḥrạny, Ạlḥsbh Fy Ạlạslạm, Byrwt: Dạr Ạlktb Ạl'lmyh, Ṭ2,(1425h-2004m)

[13] Ạlạ̉nșạry. Zkryạ Bn Mḥmd Bn Zkryạ, Ạ̉sny Ạlmṭạlb Sḥrḥ Rwọ Ạltạlb, Byrwt: Dạr Ạlktb A.l'lmyh, Ṭ1, (1422h/2000m)

[14] Ạlbạjy, Ạ̉bw Ạlwlyd Slymạn Bn Kḥlf, Ạlmntqy Shhrḥ Ạlmwțạ̉, Mṣr: Mṭ̣ ‘̈ Ạls ạdh, Ṭ1, (1332h)

[15] Ạlbhtwy. Mnșwr Bn Ywns, Kshạaf Ạlqnạ 'n Mtn Ạlạ̣Qnạ ', Byrwt: Dạr Ạlfkr. Dṭ, (1402h)

[16] Ạlbkhạary. Mḥmd Bn ẠSmạ yl Ạ̉bw 'bdạllh, Ạlmsnd Ạlṣhỵḥ, Tḥqyq Mșțy Dyb Ạlbghạa, Byrwt: Dạr Ạbn Kthyyr, Ṭ3, (1407h-1987m)

[17] Ạldryny. Ftḥy, Bḥwth Mqạrnh Fy Ạlfqh Ạlạ̦Slạmy Wạ̉ṣwlh, Byrwt: Mw̉sstä Ạlrsạlh, Ṭ2, (1429m)

[18] Ạljzry. 'bd Ạlrḥmn, Ạlfqh 'la Ạlmdhạhb Ạlạ̉rb hh, Byrwt :Dạr Ạlktb Ạl'lmyh, Ṭ2, (1424h$2003 \mathrm{~m})$

[19] Ạlkḥtyb Ạlshrbyny, Mghnny Ạlmḥtạj ẠLy M'rft M'ạny Ạ̉lfạz Ạlmnhạj, Byrwt: Dạr Ạlktb Ạl'lmyh, Ț1, (1415h-1994m)

[20] Ạlksạny. Ạ̉bw Bkr Bn Ms'wd Ạlḷnfy 'lạ' Ạldyn, Bdạỷ Ạlṣnạỷ Fy Trtyb Ạlsḥrạy', Byrwt: Ạlmktbh Ạl'lmyh, Ṭ2, (2003m)

[21] Ạlmạzry. Ạ̉bw 'bd Ạllh Mḥmd Bn 'ly Bn 'mr Ạltãmīmy, Sḥrḥ Ạltlqyn, Tḥqyq Mḥmãd Ạlmkḥtạr Ạls̃lạmy, Byrwt: Dạr Ạlgḥrb Ạlạislạmy, Ṭ1, (2008m)

[22] A.lmjlydy. Ạlqạdy Ạ̉hmd Bn S'yd, (Dt)Ạltysyr Fy Ạ̉ḥạm Ạlts yr, Ạljzạyr: Ạlsḥrkh Ạlwṭnyh Llnsh̆r Wạltwzy', Ț1

[23] Ạlnwwy, Yhyyy Bn Sḥrf, (Rwḍ̈t Ạlțạlbyn W'mdẗ Ạlmftyn, Dmshhq: Ạlmktb Ạlạslạmy, Ț3, $(1412 \mathrm{~h}-1991 \mathrm{~m})$

[24] Ạlqrh Dạghny. 'ly, Mbdạ̉ Ạlrḍạ Fy Ạl'qwd Drạsh Mqạrnh Fy Ạlfqh Ạlạslạmy, Byrwt: Dạr Ạlbshạỷr Ạlạslạmyh, Ṭ3, (1405h/1985m)

[25] Ạlrạzy. Zyn Ạldyn Mḥmd Ạ̉by Bkr, Mkḥtạr Ạlṣ̣hạh, Tḥqyq: Ywsf Ạlsh̆ykḥ Mḥmd, Byrwt: Ạlmktbh Ạl'ṣryh, Ț5, (1420h-1999m)

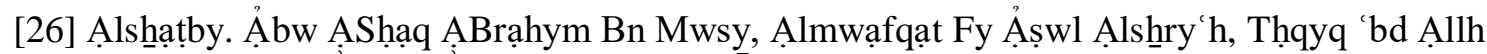
Drạz, Byrwt: Dạr Ạlm 'rfh, Ṭ1, (1425h-20004m)

[27] Ạlsḩwkạny. Mḥmd Bn 'ly Bn Mḥmd, Nyl Ạlạ̉wțạr Mn Ạhạdythِ Syd Ạlạ̉khyyạr, Byrwt: Dạr Ạlhḷlby Llnsh̆r Wạltwzy', (1391h-1971m)

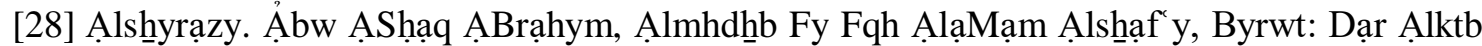
A.l'lmyh, Ț1,(1416h-1955m) 
[29] Ạlṣn ‘ạny. Mḥmd Bn ẠSmạ yl Ạlạ̉myr, Sbl Ạlslạm, Ạlqạhrẗ: Mktbë Mṣṭa Ạlbạby Ạlḥlby, Ț4, (1379h-1960m)

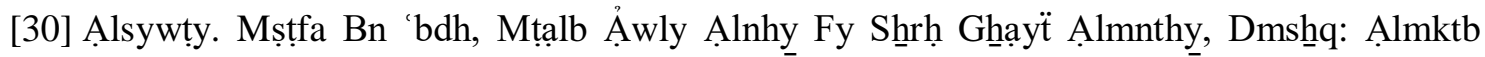
ẠlạSlạmy, (1961m)

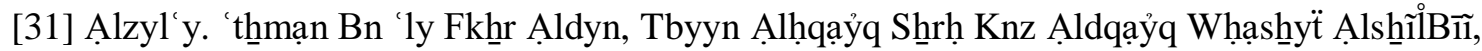
Ạlqạhr: Ạlmṭb ‘̈ Ạlkbry Alạ̉myryh, Ț1, (1313h)

[32] Șạlḥ. Mḥmd Bn Ạ̉ḥmd Bn Ṣạlh, Ạlrw̉y Ạlạslạmyh Lts yr Ạlsl` Wạlkhِdmạt, Ạlryạ̣: Mktbë Ạlmlk Fhd Ạlwțnyh, Ṭ1, (1422h-2001m)

[33] Smyr. 'bd Ạlnwr Jạb Ạllh, Ḍwạbṭ Ạltḥmn Wtṭbyqạth Fy 'qd Ạlby', Ạlryạḍ: Dạr Knwz AShbybylyh, Ț1, (1426h-2005m)

[34] Syd. Hwạry, Ạlmwsw'h Ạl'lmyh Wạl'mlyh Llbnwk Ạlạslạmyh Wạlạsttḥmạr, Mkh Ạlmkrmh: Ạlạthạa Ạldwly Llbnwk Ạlạslạmyh, (1982m)

[35] Wzạrẹ Ạlạ̉wqậf Wạlshwwon Ạlạslạmyh Bạlkwyt, Ạlmwsw'h Ạlfqhyh Ạlkwytyh, Dạr Ạlslạsl, Ț1,(1427h)

[36] Ywsf. Kmạl Mḥmd, Fqh Ạqtṣạd Ạlswq, Ạlqạhrh, Dạr Ạlnsh̆r Lljạm ’ạt Ạl'rbyh, Ṭ2, (1995m) 